\title{
UN EDÍCULO REPUBLICANO DEDICADO A ATARGATIS EN CARTHAGO NOVA
}

\author{
POR
}

\author{
SEBASTIÁN F. RAMALLO ASENSIO y ELENA RUIZ VALDERAS \\ Dep. de Prehistoria, Arqueologia, Historia Antigua e Historia Medieval. Univ. de Murcia. \\ Museo Arqueológico Municipal de Cartagena
}

\section{RESUMEN}

Se analiza un conjunto de estructuras halladas en el sector nororiental del cerro del Molinete (Cartagena). Consisten en un ediculo pavimentado con opus signimum en el que se halla inscrita una dedicación a Atargatis asociado a una serie de cubetas e instalaciones de carácter hídrico. Al lado, restos de un gran basamento que podrian constituir el podium de un templo. La cronologia de finales del siglo II a.C. indica la penetración directa de estos cultos desde oriente y su trasmisión a través de los esclavos y libertos sirios, bien documentados en la epigrafia de la ciudad.

\section{SUMMARY}

A group of architectural structures found at the NE sector of Molinete's hill in Cartagena are studied. Consisting on a sacred room and hydraulics installations with an opus signinum pavement where a dedication to Atargatis is written. Near, there is a large base that could be considered as a temple podium. The chronology at the end of the second century B.C. suggests the direct penetration of the cult from the Near East and its transmission by Syrian slaves and freedmen. well-known in Charthago Nova.

\section{INTRODUCCIÓN}

El cerro del Molinete ocupa un lugar destacado en la topografia arqueológica de Carthago Nova tanto por su situación estratégica como por la peculiar conformación que el relieve y las dimensiones le infieren; desde su cima se domina el puerto comercial antiguo situado al oeste y el estero al norte, lo que le convierte en una magnifica referencia visual para los navegantes en su aproximación a la ciudad a la vez que para sus habitantes desde el centro de la misma (fig. 1). Estas circunstancias han determinado una larga e intensa ocupación de su suelo que se ve reflejada en la gran cantidad de cimientos de distintas épocas y en la complejidad de las estructuras superpuestas. Los testimonios más antiguos acerca de dichas ocupaciones se localizan en la zona más septentrional, en el denominado sector A-1, y consisten en una serie de habitaciones alineadas construidas con muros de mampostería irregular a base de piedras desbastadas y careadas trabadas con barro y con suelos de tierra batida. Entre el material cerámico hallado en los cortes de este sector $(X / 9$ $\mathrm{Y} / 25$ a X/16-Y/26) destacan fragmentos de cerámica de barniz negro del taller de Rosas, del taller de las "pequeñas estampillas» y cerámica calena de relieve que permiten rastrear una ocupación al menos desde inicios del siglo III a.C., aunque el mayor volumen corresponde al siglo ॥ a.C. con un predominio absoluto de la campaniense A. En cualquier caso, dadas las circunstancias de la excavación, es hoy muy difícil vincular con precisión este material con las estructuras existentes, aunque sin duda permiten obtener un marco general muy aproximado del proceso y las fases de ocupación del cerro.

En este sentido, la amplia ocupación del cerro, especialmente intensa entre los siglos XVI y $\mathrm{XIX}$, ha determinado fuertes contrastes en la conservación del depósito estratigráfico que aparece muy alterado por cimientos, aljibes, pozos ciegos y basureros. Por otra parte, zonas muy amplias de la cima del cerro aparecen arrasadas hasta la roca de base, mientras que la ladera meridional, presenta un potente depósito con estratos de relleno y colmatación de época reciente. A ello hay que añadir la construcción de la muralla de Felipe II que contorneaba la cima del cerro por su ladera norte y que, como se ha podido observar posteriormente, recortó estructuras ubicadas en la ladera septentrional. Todo ello provoca una dificil lectura de la deposición estratigráfica tanto en sentido vertical como horizontal. 


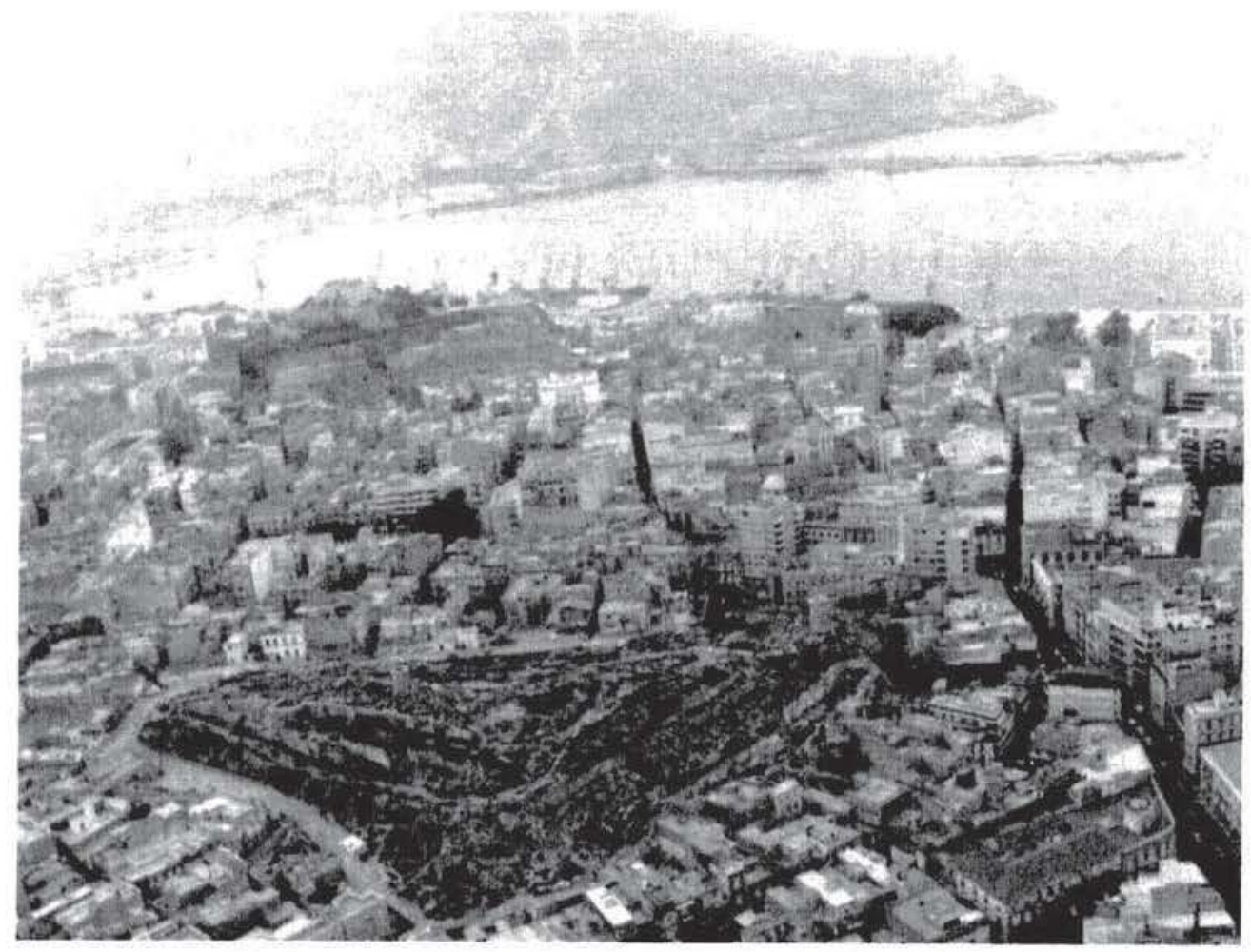

I igura 1. Ln primer termuno. ista aerea del cerro del Molinete. Al fondo. el cerro de la concepeion y el puerto (fotografia cortesia de J. Mas Giarcia).

\section{TOPOGRAFIA Y PAISAJE}

La intensa y continuada ocupación del cerro del Molinete ha transformado profundamente su fisonomia original. Sin embargo, la demolición del barrio moderno y el posterior desescombro han permitido restituir parcialmente su topografia al poner al descubierto la roca de base en amplios sectores. Presenta forma triangular, algo menos de $4 \mathrm{Ha}$. de extensión y una orientación noroeste-sureste, con una cota máxima de $34,91 \mathrm{~m}$. sobre el nivel del mar; la curva de nivel de los $10 \mathrm{~m}$. contornearía la base del cerro. Esta diferencia de casi $25 \mathrm{~m}$. se articula de distinta forma según la ladera del cerro de que se trate; asi, la cima amesetada de planta irregular presenta unas dimensiones máximas de $140 \mathrm{~m}$. de longitud y una anchura que decrece en dirección oesteeste desde los $90 \mathrm{~m}$. hasta los $35 \mathrm{~m}$. quedando delimitada por la curva de nivel de los $30 \mathrm{~m}$. En cambio, la ladera suroeste, orientada hacia el interior de la ciudad, tiene una anchura máxima de $140 \mathrm{~m}$. en su base, articulándose toda ella en una serie de terrazas, en parte producto de un recorte artificial, con desniveles que oscilan entre $\operatorname{los} 3$ y los $4 \mathrm{~m}$. Mucho más acusada es la pendiente en las laderas norte y oeste donde no se han constatado restos arqueológicos, mientras que al sur existe una segunda plata- forma amesetada, de menores dimensiones que la superior, contorneada por la curva de nivel de los $27 \mathrm{~m}$. (fig. 2). La referencia visual de esta última plataforma es mucho más acusada en el proceso de aproximación a la zona portuaria situada probablemente, al menos en parte, bajo el actual Arsenal. En este sector precisamente se ubican los restos del molino-ermita de San Cristóbal y bajo él los restos de un conjunto monumental de época romano-republicana, siendo, por tanto, junto con la plataforma superior, la zona hasta ahora más fructifera en to que a la exhumación de estructuras edilicias se refiere.

\section{HISTORIA DE LAS EXCAVACIONES}

A pésar de esta intensa ocupación y de las continuas alteraciones del subsuelo, en la historiografia local no existen referencias a hallazgos arqueológicos de interés en todo el cerro. Las escasas noticias aluden prácticamente en su totalidad a las calles que bordean el cerro por el sur y le separan del centro de la ciudad, históricamente situada en la actual plaza de San Francisco. Los primeros proyectos de intervención urbanistica sobre el Molinete que contemplan ya la total demolición del barrio alli levantado, 


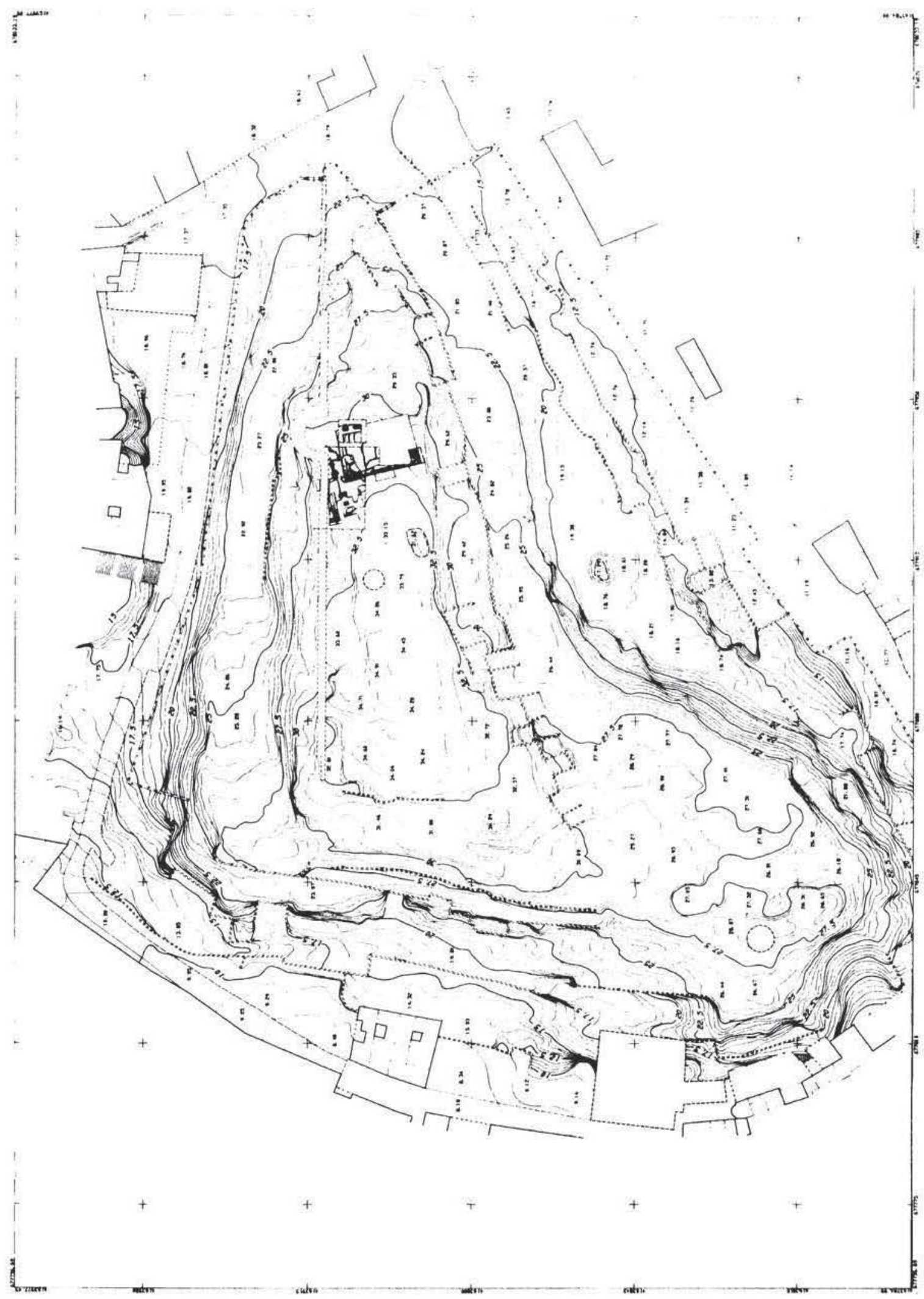

Figura 2.-Topografia del cerro del Molinete con la situación de los edificios sacros sobre cartografia original del Servicio Regional de Cartografia. C.A.R.M. E. 1:500. 
se remontan a principios del presente siglo aunque su ejecución no se lleva a cabo hasta la década de los setenta. En 1974, la Dirección General de Bellas Artes comunicó al Ayuntamiento de la ciudad la necesidad de realizar una prospección arqueológica previa a cualquier remocion de tierras; estos trabajos fueron llevados a cabo por Pedro San Martin Moro, director del Museo Arqueológico de Cartagena !

Las excavaciones se iniciaron en octubre de 1977 con noventa peones procedentes del paro obrero, bajo la dirección de San Martin y la vigilancia directa de Saturnino Agüera, guarda de monumentos del Ministerio de Cultura. Asistieron como colaboradores alumnos de la Universidad de Murcia y los entonces licenciados M. Ros Sala y J. Pérez Ballester. El yacimiento se dividió en ejes de coordenadas $\mathrm{X}$ e $\mathrm{Y}$, orientados norte-sur con cuadrículas de 6 por $6 \mathrm{~m}$. Se determinaron tres sectores de actuación que correspondian respectivamente a tres zonas distintas del cerro. El sector A, situado en la parte alta y septentrional de la colina, que discurria paralelo a la muralla del siglo xvi y que a su vez fue subdividido en los sectores A-1, el más occidental y A-2, situado hacia el este; el sector B, emplazado junto al molino-ermita de San Cristóbal, en una plataforma amesetada situada en la zona oeste del cerro; y por último el sector $\mathrm{C}$, ubicado en la ladera meridional, con su limite inferior situado en la calle de la Aurora. Los tres sectores ofrecieron resultados positivos en cuanto al hallazgo de restos arqueológicos de épocas romana y prerromana.

El sector A-1 proporcionó las habitaciones ya mencionadas mientras que en la zona más oriental (sector A-2) se pusieron al descubierto los restos de un basamento de gran envergadura situado junto a un pavimento epigráfico de opus signinum y una serie de piscinas de diferente tamaño y profundidad. En este mismo sector pero ya en la zona de ladera se halló una gran cisterna encuadrada por muros realizados por bloques regulares de basalto junto a restos de pavimento de mortero hidráulico. El sector B, proporcionó restos de habitaciones de cronología tardia superpuestas a un gran edificio de época tardo-republicana al que probablemente pertenecian varios sillares de arenisca, un friso dórico con metopas

' Las escasas referencias a estas intervenciones en San Martín, P.: La arqueologia urbana en Cartagena, I Encontro Nacional de A rqueologia Urbana. Setúbal, 1985 (Lisboa, 1986), 184, y también San Martín Moro, P. A.: Cartagena: Conservación de yacimientos arqueológicos en el casco urbano, Arqueología de las ciudades modernas superpuestas a las antiguas. Madrid, 1985. 348-349. y triglifos y una cornisa decorada con un kı̀ma jónico localizados entre las estructuras. En el sector C se constataron una serie de construcciones romanas bajo una potente capa de escombros modernos.

Los materiales arqueológicos hallados en estas excavaciones de 1977 y 1978 se encuentran almacenados en unas 500 cajas en los fondos del Museo Arqueológico Municipal de Cartagena, ordenados por cuadriculas y con referencias a las profundidades excavadas en cada uno de los cuadros. Del análisis de este material cerámico se deducen, a grandes rasgos, las siguientes consideraciones: una ocupación indigena en la parte superior del cerro atestiguada por las cerámicas de barniz negro y por las cerámicas ibéricas pintadas ${ }^{2}$; sobre este núcleo indigena se instalará, según la interpretación tradicional emanada de la lectura de Polibio, la fortaleza de Asdrubal, que de momento no podemos relacionar con estructuras de esta cronologia aunque si con algunos materiales cerámicos. Tras la conquista romana de la ciudad se aprecia un fuerte dinamismo en la ocupación de este cerro atestiguado por el gran volumen de material datable en el siglo $\|$ a.C. La ocupación del mismo continúa durante todo el período tardo-republicano hasta inicios del siglo I de nuestra era, en que se constata en la ciudad un proceso de renovación urbanística en el que el Molinete queda fuera de la nueva reordenación urbana. Tras un largo periodo de abandono se documenta de nuevo una ocupación tardía del cerro, concretamente en el sector B, constatada por la presencia de materiales cerámicos de los siglos VI-VII, en los que destacan T. S. africanas D, lucernas con motivos cristianos y cerámicas de cocina tosca local. En época medieval debió quedar abandonado a juzgar por los escasos fragmentos hallados y no se ocupará de nuevo hasta inicios del siglo xvi.

Desde las excavaciones efectuadas en 1977-78, tan sólo se han realizado dos campañas de limpie$z a$, una en 1985 y la otra en 1990, a pesar de que la importancia de este cerro en época republicana impone ya una nueva revisión de los conjuntos excavados anteriormente y en su mayoría inéditos. Con estos objetivos efectuamos en noviembre de 1993 una campaña de limpieza y dibujo de los restos arquitectónicos excavados en el sector A-2, junto a la apertura de algunos sondeos estratigráficos con el objeto de clarificar la pertenencia del basamento descubierto en 1977 a algún tipo de edificación, determinar dimensiones y funcionalidad de la mis-

${ }^{2}$ Ros Sala, M*. M.: La ciudad romana de Carthago Nova: la pervivencia del elemento indigena, Murcia, 1989. 
ma. a la ver que comprobar la existencia de posibles estratigrafias antiguas

A nuestra llegada al yacimiento pudimes comprobar que se habian realizado excavaciones bajo la habitación con pavimento de opus signimum y que los materiales originarios de esta incursión estaban abandonados sobre el pavimento y procedian de los estratos subyacentes de la habitacion. Fste material ceramico presentaba un contexto fechable en la segunda mitad del siglo 11 a.C. y se caracteriza por la presencia de campaniense A, con fondos decorados por círculos concéntricos, ánforas Dressel I A y cerámicas de cocina italicas. Tras una inicial limpicza de la superficie del area en cucstion, planteamos un primer sondeo arqueológico con la intención de conocer las dimensiones de lo que parecia el hasamento de un templo de planta itálica, cuya anchura pudimos deducir con la simple limpicza de lo ya excavado, ya que conservaba la impronta y recorte de la roca base, en la cuadricula $\times 20-Y 25$ y tan sólo faltaba ver su longitud hacia el sur: en este sondeo. efectuado junto al muro de cierre occidental. pudimos determinar varios estratos de relleno fechables entre los siglos xv11-xx. En cl frente meridional del templo ampliamos un cuadro con el objeto de precisar el acceso al edificio, obteniendo la secuencia siguiente: sobre la roca base aparece el recorte de una rampa de acceso al templo y excavada en esta rampa encontramos una fosa de casi un metro de profundidad colmatada con materiales de los siglos vi-vil, entre los que destaca ceramica de cocina tosca local, un anfora africana Keay XXXIII y una importante cantidad de huesos de animales. Este conjunto cerrado es muy similar a los basureros de época bizantina localizados en el resto de la ciudad. Sobre la roca base y cubriendo este basurero individualizamos un relleno con materiales del siglo xvxvII y sobre éste varios estratos de relleno; por ultimo, el suelo y los muros de una vivienda moderna cubrian la totalidad del depósito.

De la nueva revisión estratigráfica se deduce que el depósito antiguo debió conservarse junto a la muralla del siglo xvı, cuya construcción cortó los niveles arqueológicos subyacentes pero los contu-

\footnotetext{
' Somos conscientes del caracter provisional de los datos y de las conclusiones que se presentan en este primer estudio. Sin embargo, la novedad e interés de la informacion y la imposibilidad de realizar nuevas intervenciones en extension en el yacimiento a corto y medio plazo en tanto no se clarifique su situación y proyección urbanistica y se adopte una decisión definitiva para la conservacion de los restos arqueológicos del Molinete. nos han llevado a realizar esta primera aportacion, conscientes de las nuevas perspectivas que puede abrir para la reconstrucción de la ciudad romana
}

wo en esta ladera norte: mientras que, por el contrario. la cona central y la mona meridional, mas elesadas. quedaron muy arrasadas por las construcciones modemas realizadas a partir del sigle IW. eomo parece desprenderse de los sondeos efectuados en esta parte

\section{DESC RIPCIONDE I ASFSTRI CTIRAS}

Como adelantabamos en lineas anteriores, sobre la ya citada cima amesetada se ubica un edificio de planta rectangular y orientado $\mathrm{N}()$-St. cuyos muros se levantan sobre una plataforma que nivela el terreno, realizada con sillares de arenisea de unas dimensiones medias de $0.45 \mathrm{~m}$. de ancho por 0.80 $1.00 \mathrm{~m}$. de largo, colocados a soga y tizon. con unas dimensiones de $11.20 \mathrm{~m}$. de ancho por $16.75 \mathrm{~m}$. de largo (fig. 3). Sobre esta plataforma se levantan los muros del podium que cierran en su interior el nucleo del basamento. el cual aprovecha una elevación de la roca natural ligada con caementicium a los muros de cierre. Del al/ado exterior de estos muros se conservan cinco filas de bloques de basalto: la primera retranqueada unos $14 \mathrm{~cm}$. respecto a la plataforma. con bloques de $34-30 \mathrm{~cm}$. de largo por $22 \mathrm{~cm}$. de alto: la segunda retranqueada igualmente $14 \mathrm{~cm}$. respecto de la primera. presenta bloques de 24 a $10 \mathrm{~cm}$. de largo por $16 \mathrm{~cm}$. de alto. Las tres hiladas restantes, con bloques más regulares de 34 a $20 \mathrm{~cm}$. de largo por $20 \mathrm{~cm}$. de alto, se escalonan $10 \mathrm{~cm}$. respecto de la anterior. dando todo ello un total de $98 \mathrm{~cm}$. de al/ado conservado (figs. 4 y 5 ).

En un principio hay que sospechar al menos la falta de otra hilada de $20 \mathrm{~cm}$. que daria un total aproximado de $0.80 \mathrm{~m}$. para el cuerpo central del basamento al que habria que superponer unos $38 \mathrm{~cm}$. de la moldura de remate superior del podium, con un

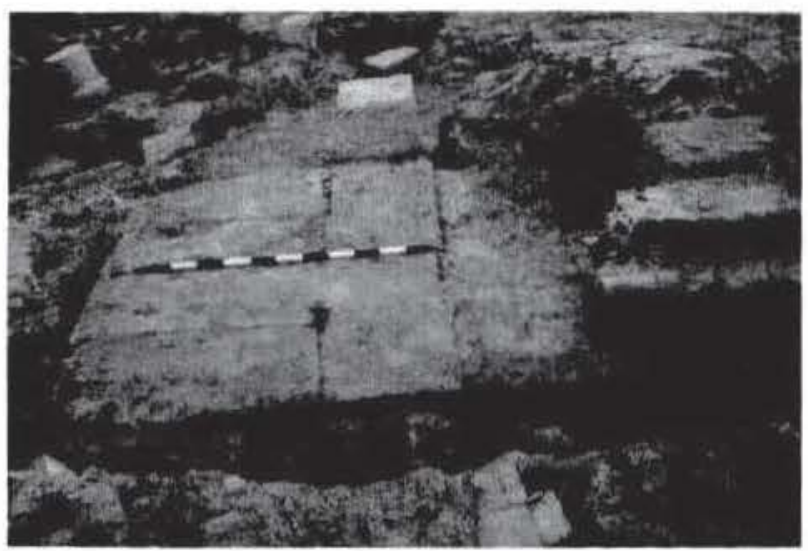

Figura 3. Detalle de la plataforma de arenisea del templo. 


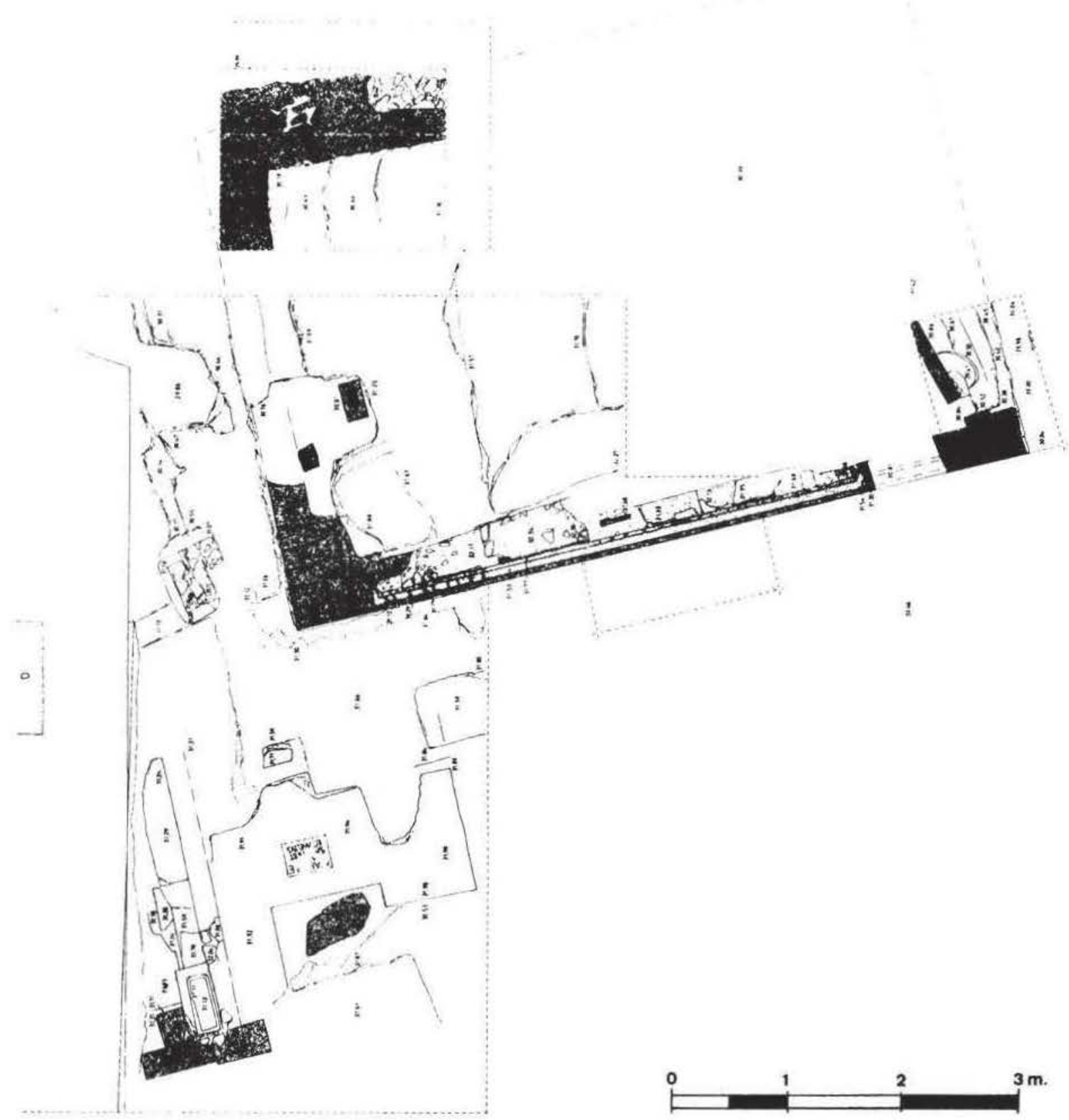

Figura 4.-Planimetria del templo y del ediculo de Atargatis. E. 1:160.

total de altura estimada de $1,60 \mathrm{~m}$., alzado que enrasa en gran medida con el nivel de roca recortado (figs. 6 y 8). Este alzado se ha conservado en el frente occidental del edificio mientras en el lado oriental, hasta ahora excavado, ha desaparecido por completo. En este lado se han podido determinar las dimensiones del basamento por los recortes de la roca, que permiten reconocer el ángulo noreste y por las huellas de los sillares de arenisca disgregados sobre la roca de base.

En el frente sur, orientado hacia el centro de la ciudad, que correspondería a la fachada y a la escalera monumental de acceso al edificio, se ha podido reconocer sólo la rampa recortada sobre la roca sobre la que posteriormente asentaban los peldaños, flanqueada por sillares de arenisca que determina- 


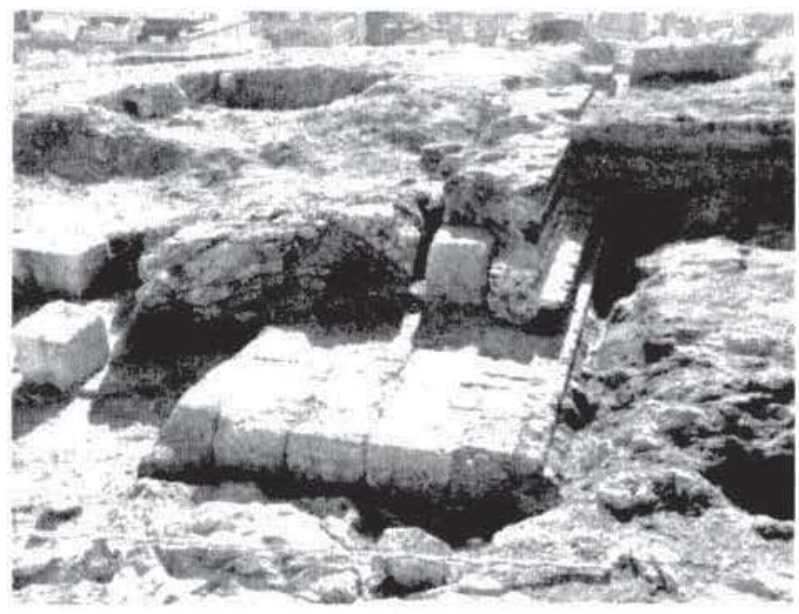

Hetaras. Vista lateral del templocon la platitorma de arenisca y el alrado del polium.

ban un saliente de $c .1 .00 \mathrm{~m}$. de anchura incluida la moldura inferior. En principio, si aceptamos dos antas de $c$. $1 \mathrm{~m}$. a ambos lados, la anchura estimada para esta escalinata frontal seria de $9.20 \mathrm{~m}$.

Fin el ángulo noroeste del edificio se extienden las estructuras de un conjunto sacro compuesto por un pequeño ediculo y una sala con piscina. La capiIla tiene unas dimensiones de $4.50 \mathrm{~m}$. de larga por $5.57 \mathrm{~m}$. de ancha y el ingreso se realiza por el lado este a través de una entrada, de 1.00 ó $1.50 \mathrm{~m}$. de anchura, con escalones. En el interior y en el eje de la entrada encontramos la dedicación del ediculo. inscripción enmarcada por una cartela de $0.75 \mathrm{~m}$. de ancha por $1,00 \mathrm{~m}$. de larga, realizada con teselas blancas de $10-12 \mathrm{~mm}$. de lado y colocada delante de un espacio $\sin$ pavimentar de $2,30 \mathrm{~m}$. de ancho por $2.50 \mathrm{~m}$. de largo, que podria estar ocupado por un altar para sacrificios o quizá por un pedestal con la imagen de la divinidad. Al oeste del mismo y unido a él, encontramos otro espacio sin pavimento de $1,70 \mathrm{~m}$. de ancho por $2,00 \mathrm{~m}$. de largo, donde podemos ubicar una posible cubeta que recogiera y canalizara los restos del sacrificio realizado junto al altar, o bien una banqueta adosada al muro de cierre oeste de la capilla (fig. 7).

El edificio está pavimentado con opus signinum de color rojizo con un preparado de cal, arena y cerámica machacada y con un ruchus de piedra mediana. La inscripción se puede transcribir de la siguiente forma: en el primer renglón el nombre de la divinidad A[T]AR [G]ATE con letras de $15 \mathrm{~cm}$. de altura: el segundo renglón apenas se lee, $\mathrm{A}[-\ldots]$ que puede

Figuras 6 y 7.-Alzado del podium del templo y sección transversal del ediculo de Atargatis en relación con el templo. E. 1:100.

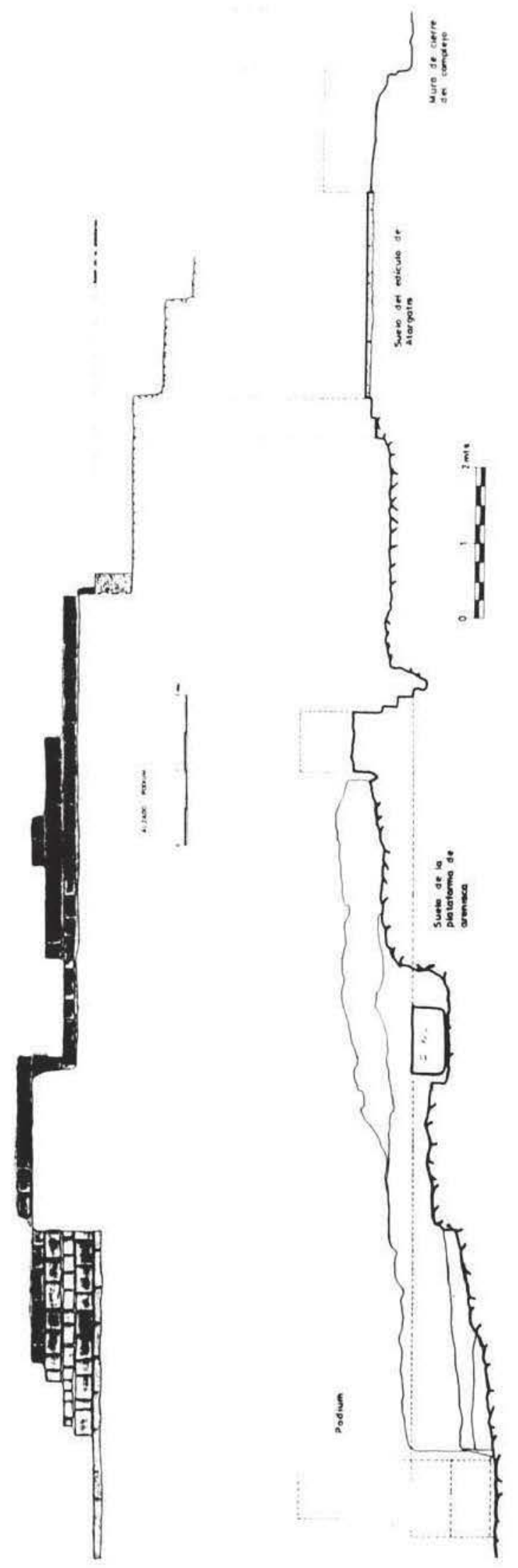

http://aespa.revistas.csic.es/index.php/aespa 


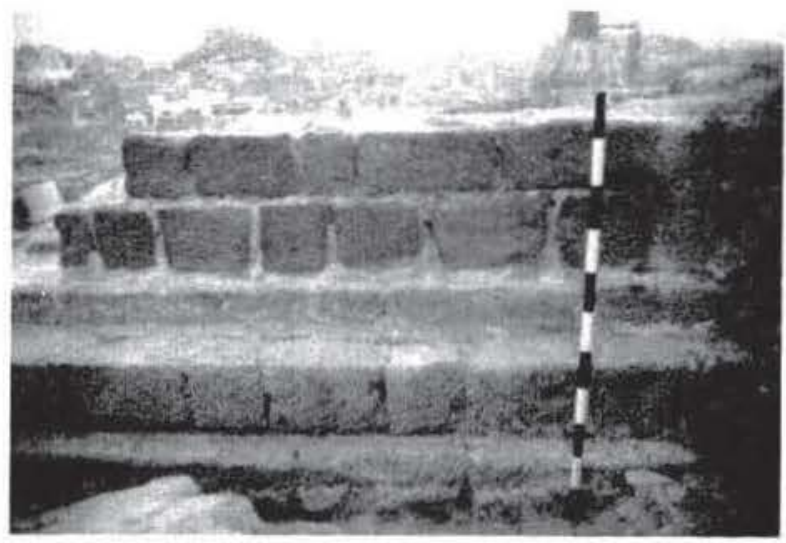

I tguras. Detalle det alzado dei pordrum det templo

hacer referencia a un apelativo de la divinidad o bien al objeto que se le dedica, con letras de $10 \mathrm{~cm}$. de altura: tras la primera letra parece intuirse el arranque de una $\mathrm{N}$. aunque és imposible asegurarlo dado que tan sólo se conservan tres pequeñas teselas del angulo superior izquierdo de la letra '; la tercera letra se ha perdido por completo, mientras que la cuarta. por descarte podria considerarse si tenemos en cuenta la forma de la rotura y una tesela que se conserva entre las letras 6 y 7 de la segunda linea, una $\mathrm{A}$, una $\mathrm{M}$ o también una $\mathrm{E}$. En el tercer y cuarto renglón parece clara la förmula SA[LV]TE ET/EO MELIVS, con letras de $12.10 \mathrm{~cm}$. (fig 9). Hasta ahora, que nosotros sepamos, es la única inscripción sobre pavimento donde aparece el nombre original de la diosa en caracteres latinos. Sus paralelos más próximos se hallan siempre en ciudades del Mediterráneo oriental asi como en la isla de Delos donde siempre aparece con caracteres griegos. En el Mediterraneo central y occidental se difunde con el nombre romano de la Deo Siria.

\footnotetext{
'Hepiteto más común en las inscripciones delias es ' $\alpha \gamma v$ í. entendida como epura, casta o santaw, asi por ejemplo, en ID. 2266.

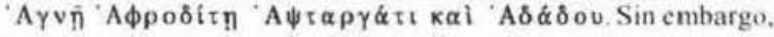
a no ser que se tratara de una transliteración. no conocemos un epiteto con el mismo significado y que empiece por $\Lambda+3$ letras

FI pavimento fue analizado y reproducido en Ramallo, $S$ : Mosaces romanos de. (arthago Nova (Hispania citerior). Murcia. 1985, aunque en esta obra tan sólo pudimos restituir la lectura de las dos ultimas lineas. La interpretación final de la inseripcion se la debemos al Dr. M. Mayer a quien se la mostramos. junto a los primeros planos recogidos de actuaciones anteriores a la nuestra. en el congreso de Tarragona de septiembre de 1993 y poco después nos ofrecia a través de la Dra. 1. Rodá, su interpretación de la primera linea. Debemos agradecer el interés y las múltiples observaciones que tanto el Dr. Mayer como la Dra. Rodá nos han aportado durante todo el proceso de realizacion y elaboracion de este proyecto de investigación.
}

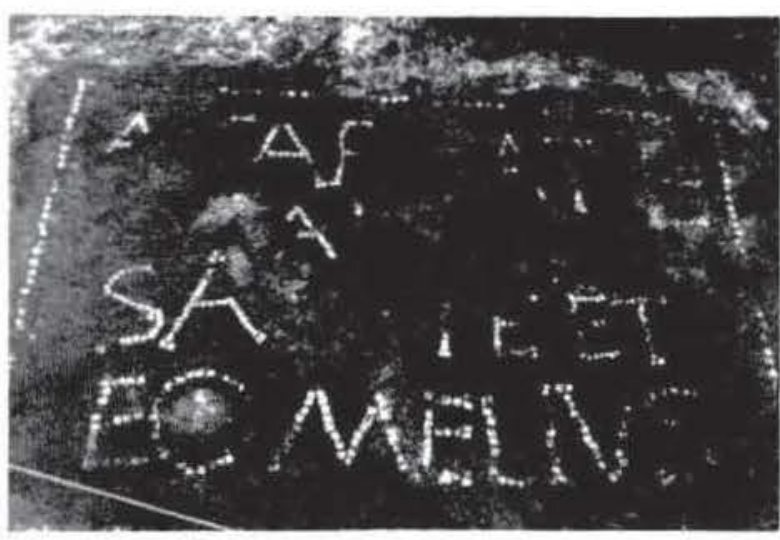

tiguray Inscripcion wolma sobre el pasimento de opmes signinium (nce Ana $\mathrm{M}^{+} \mathrm{M}$ (uños)

El ediculo esta separado al norte por un muro. muy arrasado y de unes $50 \mathrm{~cm}$. de ancho, de la sala de la piscina. En este muro se intuye un acceso con escalones, de unos $95 \mathrm{~cm}$. de ancho, que conduce directamente al suelo de la piscina. En la parte oeste de esta sala se conservan los cimientos del muro que cierra todo el conjunto por este lado: dichos cimientos están realizados con grandes sillares de arenisca con unas dimensiones medias de $0.60-0.70 \mathrm{~m}$. de ancho y $1.25-1,60 \mathrm{~m}$. de largo. Adosadas al muro de cierre y al medianero con el ediculo, aparecen sendas banquetas revestidas de opus signimum de unos $50 \mathrm{~cm}$. de ancho; en la esquina entre ambas se sitúa una pequeña pileta con los ángulos reforzados con media caña. con unas dimensiones de $1,30 \mathrm{~m}$. de larga por $0.50 \mathrm{~m}$. de ancha y $0.60 \mathrm{~m}$. de profundidad. El suelo de esta pileta está $8 \mathrm{~cm}$. más elevado que el de la piscina, de manera que el agua de la pileta se vierte por medio de una tuberia de plomo, situada en el fondo de la pileta, en la piscina mayor. Los ángulos rectos entre las paredes y el suelo de la piscina están protegidos por una media caña de $12 \mathrm{~cm}$. de ancha por $10 \mathrm{~cm}$. de alta (fig. 10).

En la parte oriental de la sala y al otro lado de los escalones, se conservan los restos de un pavimento de signimum vinculado claramente a este conjunto. cuyo suelo aparece $14 \mathrm{~cm}$. más elevado que el de la piscina anterior. Todas estas estructuras aparecen cortadas en su zona norte por la construcción de la muralla del siglo xvi, por lo que resulta imposible reconstruir sus dimensiones precisas.

En la parte norte del edificio monumental y separado del mismo unos dos metros, apareció en las excavaciones de 1977-1978 una alineación de ánforas tipo Maña $\mathrm{C} 2$, colocadas de forma paralela a la plataforma del edificio, y encajadas en una estrecha 


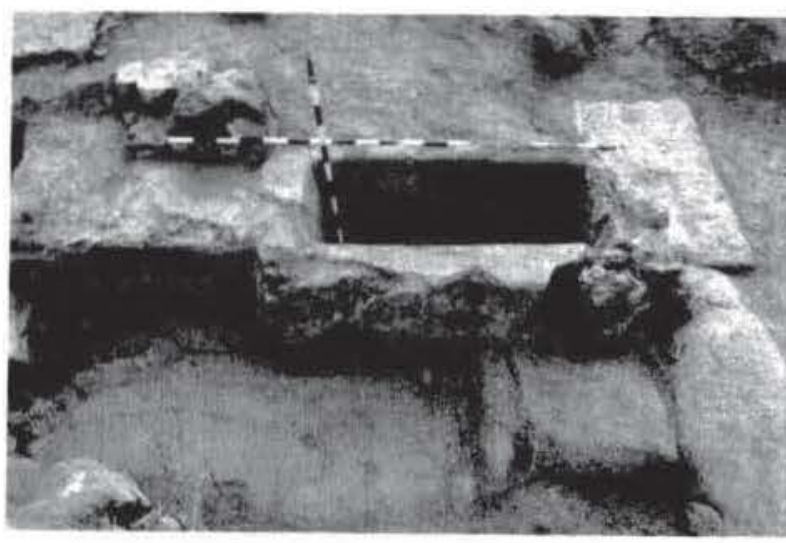

Figura 10. Instalaciones hidraulicas jeinto al ediculo do Atargatis. Detalle de la pileta y la piscina.

zanja de unos $35 \mathrm{~cm}$. de anchura. Este filtro de anforas también puede tener relación con la sala de la piscina del conjunto anterior, separado del mismo unos cinco metros ${ }^{6}$ (fig. 11 ).

En la parte oriental de este conjunto, conforme desciende la superficie del monte, son visibles los restos de una gran cisterna situada a unos diez metros del muro de cierre del edificio monumental y en el eje con el posible filtro de ánforas. De la cisterna se conservan parte de los muros del sur y oeste, de unos $60 \mathrm{~cm}$, de anchura, realizados con bloques regulares de basalto trabados con cal y revestidos con mortero hidráulico; el muro sur se conserva en unos siete metros de longitud. El resto de la estructura de la cisterna aparece cortado por la fortificación del siglo xvı aunque se observa su continuación al otro lado de la muralla. Al sur de la cisterna se identifica una canalización y los restos de un pavimento de signinum con unas dimensiones de $2,50 \mathrm{~m}$. de ancho por $4,30 \mathrm{~m}$. de largo.

\section{EL. CULTO A ATARGATIS Y SU DIFUSIÓN EN EL MEDITERRÁNEO OCCIDENTAL}

La Dea Syria de los romanos, Atargatis entre los sirios o también conocida como Derceto en Ascalón, era la divinidad femenina más importante del panteón sirio. El mayor centro de culto se hallaba en Hierápolis, la antigua ciudad de Bambyke

* El paralelo más inmediato nos lo proporciona la Neapolis de Ampurias interpretado como un filtro de carácter cultual. También interpretadas en un contexto de almacén puede verse en Fernández Izquierdo. A.: El poblado ibérico de Torre la Sal (Ribera de Cabanes, Castellón): Campaña de excavaciones 1985. 1988. CuadCastellón, 13, 1987-88, 236-238, lám. II.

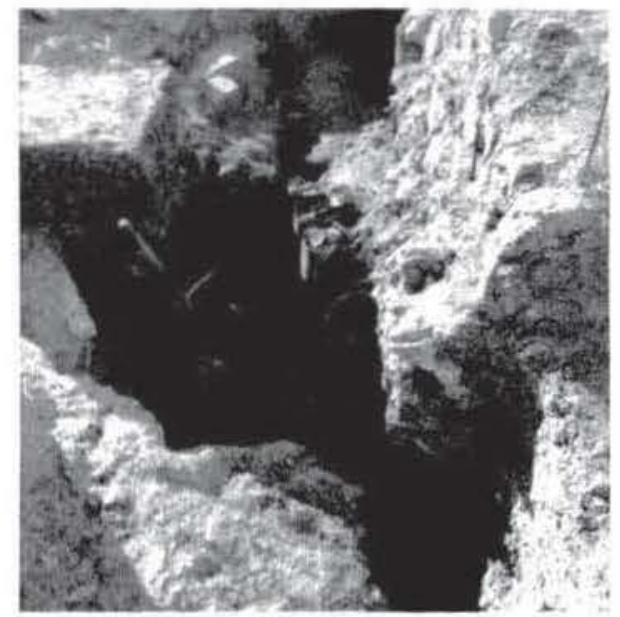

Figura II filtre de antoras cheafodis en la reca base y st tuadas en la parte norte del conjunto (neg. P. A. San Martín)

(Mabbug). situada en el norte de Siria cuyo templo habia sido reconstruido, segun Luciano (D.S. 17-18) en orden jonico por Estratonice, esposa de Seleuco Nicátor, poce después del 300 a.C. Según el autor de Samosata, la reina habria tenido un sueño en el que Hera le habria ordenado erigirle un templo en la ciudad sagrada. Este se hallaba sobre una colina situada aproximadamente en el centro de la ciudad y estaba rodeado por un doble muro; orientado hacia levante. tenia un recinto interior sin puertas al que sólo podian acceder los sacerdotes más próximos a los dioses y aquéllos que tenian a su cargo el cuidado del templo? En él se hallaban las estatuas de Hera (Atargatis), conducida por leones ${ }^{8}$ y Zeus (Hadad) sentado sobre toros (Luc. D.S. 28-30). Sobre la fundación del santuario original circulaban distintas interpretaciones; se atribuia a Deucalión que lo habria dedicado a Hera, a Semiramis que lo habria consagrado a su propia madre Derceto, a Attis que lo habria construido para la diosa Rhea o a Dioniso (Luc. D.S. 12-16).

Existe ya una edición en castellano de la obra de Luciano con traducción y aparato critico de J.Zaragoza Botella, editada en la Biblioteca Clasica Gredos (B.C.G. 138, Luciano. Obras. vol. III). Para el texto original se ha seguido la edición do M. D. Macleod, Luciani Opera, vol. III, de la Oxford Classical Texts. 1980. Las restantes fuentes literarias alusivas a la Dea Syria se hallan recopiladas en Van Berg. P. L., Repertoire dex sources grecques et latines sur la Dea Siria. Corpus ( 'ultus Deae Siriac, (EPRO, vol XXVIII). Leiden 1972, Vid tambien, Cumont. F.: RE. s.v. Dea Suria, col. $2236-2243$.

" Desde el punto de vista iconográfico se ha señalado la identidad de estas representaciones con los tipos utilizados para la Magna Mater y Cibeles. A veces se representa también desnuda hasta la cintura, con polos y collar, trenzas que caen sobre las espaldas y con las manos en el acto de apretar los senos. Otras veces la diosa porta el timón y la cornucopia fruto de su asimilación a la $\tau$ ó $\chi \eta$ griega o la Fortuna romana. EA.A, s, v. Atargatis. vol. I. p. 12 
En los santuarios dedicados a esta divinidad un elemento imprescindible era el estanque sagrado donde se criaban peces, que no podian ser capturados ni comidos salvo para los sacrificios y sólo por determinados sacerdotes. Este carácter sacro estaba muy vinculado con distintas leyendas que corrian en torno al origen de la diosa, que incluso a veces era representada con la mitad inferior del cuerpo en forma de pez ${ }^{4}$. También en el santuario existia un espacio reservado para bueyes, caballos, osos y leones, todos ellos domesticados, que eran asimismo considerados animales sagrados (Luc. D.S. 41).

Todo esto estaba en estrecha relación con su carácter de gran diosa de la naturaleza que era considerada además, en asociación con su pareja masculina Hadad, diosa de la fertilidad y la vida y protectora de las ciudades en que se le rendía culto y de ahi la torre que en las representaciones iconográficas coronaba su cabeza ${ }^{10}$.

El culto a Atargatis estuvo muy difundido en Siria y Mesopotamia donde se produjo una asimilación con las principales divinidades femeninas de los diversos pueblos y ciudades, aunque siempre debieron permanecer ciertas diferencias locales que se reflejaban en numerosas facetas atribuidas a la diosa ${ }^{1 !}$. Su culto se propagó hasta los más recónditos lugares del Imperio a través de comerciantes y esclavos sirios que, sobre todo en el siglo ॥ a.C., afluyeron hasta los más importantes puertos del Mediterráneo. Centros importantes de culto fueron los de Edes$\mathrm{sa}^{12}$, Harrán, Nisibis, Heliópolis ${ }^{13}$, Damasco, Dura Europos ${ }^{14}$ y Palmira ${ }^{15}$. En Ascalón la diosa era ad-

"Luc. D.S., 14. Las leyendas que se contaban de la diosa han sido recogidas por Cumont F., en Daremberg-Saglio, S.v. Syria Dea. p. 1594. Según una de ellas, los peces habrian encontrado un huevo de grandes dimensiones en el Eufrates y lo habrian depositado en la orilla donde habria sido incubado por las palomas, dando nacimiento a la Dea Syria. En otra versión, la diosa habria caido al estanque de Bambyque de donde habria sido salvada por los peces. En otra leyenda, la diosa y su hijo Cupidón se habrian arrojado al Eufrates para huir de Typhon, y alli habrian sido transformados en peces. Por último, en otra versión, la diosa avergonzada por un desliz cometido con el joven Syrio se habria arrojado al estanque sagrado donde habría sido transformada en pez; en esta versión la hija concebida habria sido alimentada por las palomas. De ahi el carácter sagrado que estos animales tenian en el entorno de la mitología de la diosa.

to Cumont, F., en Daremberg-Saglio, s.v. Syria dea, p. 1593.

1 Drijvers, H. J. W.: Die Dea Syria und andere syrische Gotheiten im Imperium Romanum, EPRO, 1981, 245.

12 Drijvers, H. J. W.: Die Götter Edessas, Studien zur Religion und Kultur Kleineasiens (EPRO, 67), 1978, especialmente 279-280.

${ }^{13}$ Dussaud, R.: Temples et cultes de la triade héliopolitaine a Ba'albeck, Syria 23, 1942, 33-76, especialmente 33-38.

14 Drijvers, H. J. W.: Op. cit. (n. 11), 245. Cesano, L., en De Ruggiero, Dizionario epigrafico, s.v. Dea Syria, p. 1468.

is Teixidor, J.: The Pantheon of Palmira, Leiden 1979, 71. 76 con análisis filológico del nombre de Atargatis. vocada bajo el nombre de Derceto, nombre que también recoge Estrabón (Geogr. 16.4.27). Particularmente importante fue su veneración en Delos donde el culto era administrado desde finales del siglo 11 a.C. por sacerdotes atenienses ${ }^{16}$. Con la expansión romana y siguiendo las rutas de conquista, soldados de las legiones y tropas auxiliares se convirtieron en el principal vehiculo de propagación del culto a la divinidad. Paralelamente, sacerdotes y fieles ambulantes, que celebraban los ritos alrededor de imágenes portátiles de la diosa, alcanzaban poblaciones de menor entidad e incluso latifundios y explotaciones agricolas donde eran numerosos los esclavos o libertos sirios, que mantenian vivas sus tradiciones religiosas (Apul. VIII, 27).

En Roma se constata el culto desde la época neroniana, aunque su introducción se debió producir en el siglo II a. C., agrupándose muy probablemente en conexión con otros cultos orientales, en la zona portuaria del Tiber, lugar de máxima concentración de mercaderes orientales así como de libertos y esclavos de esta misma procedencia. Se ha vinculado también con esta divinidad el santuario hallado en el Gianicolo ${ }^{17}$ aunque los principales testimonios

in Una inscripción del 128 a.C. recuerda la dedicatoria de un edificio y de algunos altares a Hadad y Atargatis, realizados por el sacerdote de Hierápolis Achaios vid. Sfameni Gasparro, G. La religione del mondo ellenistico-romano. Storia delle religione, Roma, 1971, 423 ss. Bruneau, Ph.: Recherches sur les cultes de Délos à l'epoque hellenistique et à l'epoque imperiale. BEFAR, 217, 1970.

17 Sobre el santuario de Gianicolo, vid. entre otros Nicole, G. y Darer, G.: Le santuaire des dieur orientaux au Janicule. Roma, 1909. Gauckler, P.: Le sanctuaire syrien du Janicule, Paris 1912 y más recientemente, Goodhue, N., The lucus Furrinue and the Syrian Sanctuary on the Janiculun. Amsterdam 1975. Las excavaciones fueron realizadas por Gauckler en 1906 y se individualizaron tres fases distintas. El primitivo santuario estaba dedicado a la ninfa (o a las ninfas) Furrina, como parece deducirse de una inscripción hallada en este lugar dedicada a lupiter Kerannios y a la ninfa citada. A este período corresponderia el muro de cierre del períbolo del lucus y los restos de una canalización identificados bajo los muros del templo. La segunda fase estaba representada por un largo muro de aterrazamiento al que se adosaban dos estancias paralelas pavimentadas con mosaico, y por alineaciones regulares de ánforas situadas a un nivel inferior y dispuestas, bien clavadas sobre la punta o bien acostadas sobre la panza. Las estructuras de esta fase mantienen aún la orientación del edificio precedente norte-sur y su construcción se sitúa a finales del siglo ॥ d.C. Sobre este edificio se construye en el siglo IV el santuario más monumental formado por tres sectores unidos entre si pero diferentes en su forma. La orientación del nuevo conjunto es ligeramente divergente respecto al anterior. El centro lo ocupa un gran patio rectangular donde se abre el ingreso principal situado en el muro sur. Al este se adosa un segundo cuerpo de forma mixtilinea, mientras que en el extremo opuesto cierra el conjunto un edificio de planta basilical precedido por una especie de nártex dividido en sentido transversal por tres habitaciones comunicadas tan sólo longitudinalmente. El edificio basilical presenta una nave central terminada en forma absidial y rematada por un nicho hemisférico de grandes di- 
proceden de la zona de los Orti Mattei, donde a juzgar por las inscripciones pudo existir otro importante centro de culto a la Dea Siria ${ }^{1 x}$. Otros testimonios de la difusión del culto provienen de Amiterno, Baia, Gnatia ${ }^{14}$, Brindisi ${ }^{20}$ y Pozzuoli, donde existía un templo dedicado a Iupiter Damascenus, interpretación del dios Hadad, pareja divina de Atargatis en el templo de Damasco". En Sicilia una sublevación de esclavos del 134 a.C. fue auspiciada por Eunus, seguidor de Atargatis, inspirado por la diosa ${ }^{22}$. Fuera de Italia la diosa, en cualquiera de sus acepciones, se halla documentada ya en plena época imperial en Britania ${ }^{23}$, Galia ${ }^{24}$, Dalmacia, Panonia y Dacia ${ }^{25}$.

mensiones, flanqueados por otros más pequeños, mientras que las dos naves laterales, más estrechas, terminan en sendas exedras cuadrangulares. En el nicho central estaria situada, según F. Coarelli, la estatua de hupiter Heliopolitano (Hadad) mientras que en las laterales, se hallarian las de Atargatis (Dea Syria) y Silmios (identificado con Mercurio), vid. Guida archeologicu di Roma, Verona, 1975, 316-318. Drijvers, op, (it. (n. 11), 246 piensa por el contrario que el culto se habria establecido en la zona del Trastevere o en sus alrededores y que el santuario del Gianicolo, que probablemente estaba dedicado a Iupiter Heliopolitanus, no tenia nada que ver con la Dea Syria.

ik Coarelli, F.: I culti orientali in Roma, La Soteriologia de Culti orientali nel Imperio romano. Roma. 1979. (Leiden), 33 66 , especialmente 50-53, sugiere los Horrea Galbana como posible emplazamiento para los cultos siriacos ya que en esta zona se concentraban desde finales del siglo $\|$ a.C. grandes masas de esclavos.

iv Stazio, A.: La documentazione archeologica in Puglia. IV Convegno Magna Grecia. Nápoles 1965, 153-179 y Donuvito, A.: Egnazia. Dalle origini alle riscoperta archeologica, Brindisi, 1989, 40-42; sobre un altar o basamento de estatua compuesta por cuatro lastras aparecen en relieve instrumentos musicales en tres de ellas (flauta y tímpano) y en su cara principal una dedicatoria a la Magna Mater y a la Dea Syria. En la estancia del hallazgo se localizaron también una estatua fragmentada de Attis, un relieve con escena de banquete y una terracota femenina con la figura de Cibeles. Es interesante destacar en este caso el carácter salutifero de algunos de los hallazgos y al mismo tiempo la naturaleza pantanosa del sector situado al pie de la acrópolis que, inmediatamente, nos recuerda el paisaje de Car. thago Nova.

20 Silvestrini, M.: Culti orientali a Brindisi. CIL IX, 6099 Richerches e studi. Brindisi 1987, 175-185. Es muy interesante el texto de la inscripción donde aparecen asociadas Atargatis 1 Cibeles con un sacerdote común, L. Pacilius Taur(us) sac(erdos) matr(is) Magn(ae) Suriae deae et saccror(um) Isidis.

21 Drijvers, op cit. (n. 11), p.250. Tran Tan Tinh, V.: Le culte des divinités orientales en Campania, EPRO, Leiden, 1972 sobre un fragmento de columna de mármol se reconoce la inscripción -...-. et Leontoxasma deae d(omina) dasyr(ia) posuer(unt).

${ }^{22}$ Gaspono, G. S.: I culti orientali in Sicilia, EPRO, Leiden 1973, 163. Una inscripción siracusana atestigua además la existencia, años más tarde, de un sodalicio vinculado con el culto a la diosa.

${ }^{23}$ Birley, E.: The deities of Roman Britain, ANRW II, 18,1, 78-79.

24 Turcan, R.: Les religions orientales en Gaule Narbonnaise, ANRW II, 18, 1, 511.

${ }^{25}$ Sanie, S.: Die syrischen und palmyrenischen Kulte im römischen Dakien, $A N R W$ II, 18, 2, 1023-1025.

\section{SINCRETISMOS, ASIMILACIONES Y ASOCIACIONES}

En oriente ya hemos visto como el paredro habitual de la diosa es el dios sirio Hadad. Sin embargo, en su difusion hacia occidente, y especialmente a partir del culto en el santuario delio, se observa una separación entre ambos cada vez mayor y la preeminencia en las ciudades de un culto independiente a la Dea Siria, hermanada a veces con otras divinidades. En el ya mencionado santuario de Delos, Atargatis aparece asociada a Hadad en una inscripción dedicada por Achaios, sacerdote hierapolitano, en el 128/7 a.C. (ID. 2226); a estas mismas divinidades consagra Diophantos la gran escalera del santuario, en un momento anterior al $118 / 7$ a.C. (ID. 2283), mientras que la misma pareja junto a Asklepios forman una triada a la que, en un momento anterior al $118 / 7$ a.C.. se dedica también un edículo y otras construcciones anexas (ID. 2247). A partir del 118 a.C. el santuario es regido por sacerdotes atenienses y la Atargatis siria es ahora asimilada a Afrodita, a la que incluso a veces se añade el apelativo de Siria.

A Hadad, Afrodita y Asklepios dedica un grupo de terapeutas la exedra en el año $112 / 111$, mientras que otras dedicaciones a título privado corresponden a 1sidoro de Hierápolis (ID. 2261) y a Aristides de Lacodia (ID. 2264) ${ }^{26}$. Esta asociación a Asklepios incide en parte en el carácter salutífero de la diosa y podría estar en relación con todo el conjunto hídrico que en el conjunto de Cartagena se asocia al edículo de culto. En este sentido también cabe destacar la inscripción délica sobre plomo (ID. 2233) ofrecida a Hygiae y a la Dea Syria. En cierto modo, ese mismo carácter podria deducirse también de la fórmula pro salute - - -Aug(usti) Germanici empleada en una dedicación Deae Syryae hallada en Roma (CIL. VI, 116). Por otra parte, en ambiente fenicio una asociación similar se produce entre Eshmun y Astarté en el santuario de Bostan, cerca de Sidón ${ }^{27}$ y está clara la asimilación del dios púnico con el Esculapio griego e incluso la identidad iconográfica y también de cualidades entre la fenicia Astarté y la siria Atargatis. En Nora está asimismo atestiguado el culto a una divinidad salutífera, probable-

2n Will, E.: Le sanctuaire de la Déesse Syrienne à Delos. Exploration Archeologique de Delos, vol. 35 París 1985, 108 para el cuadro cronológico de las construcciones.

${ }^{27}$ Dunand, M.: La piscine du trône d'Astarté dans le temple D'Echmoun à Sidon, Bull. du Musée de Beyrouth. XXIV. París $1972,19-25$. 
mente Eshmun, asociado a una divinidad femenina que se ha querido identificar con la Tánit púnica ${ }^{2 n}$.

En Dura Europos el culto de Atargatis aparece asociado a Adonis aunque parece tratarse de un caso único :". Por el contrario, más frecuente es la unión. al menos en dedicatorias comunes, de la Dea Siria y la Magna Mater (Cibeles) con la que además comparte muchos elementos iconográficos y con la que ademas pudo llegar a confundirse. Apuleyo (Met. IX, I0) les Ilama Deum mater soror Deae Siriac. Esta asociación se repite en las inscripciones de Brindisi (CIL. IX, 6099) y Gnatia y también en un decreto del año 96 a.C. procedente del Pireo. En Roma la dedicación es a la mater deor(um) y a la mater Siriae (CIL. VI, 30970). También una inscripción tasia parece reflejar, aunque con algunos problemas de identificación, esta asociación entre ambas divinidades ${ }^{311} \mathrm{e}$ incluso, desde el punto de vista iconográfico. Turcan sugiere su presencia en una escena de sacrificio metroaco de un bajo-relieve hallado en Vienne ${ }^{31}$.

En cualquier caso, y al margen de estos sincretismos y asociaciones, conviene recalcar el carácter de divinidad aislada que adquiere la diosa en su expansión hacia occidente.

\section{ANÁLISIS DE LAS ESTRUCTURAS}

Desde el punto de vista tipológico, hay que distinguir, en primer lugar, la existencia de dos posibles edificios de culto encuadrados en un mismo complejo pero individualizados entre sí. El más monumental, y en consecuencia, de mayores dimensiones, corresponde probablemente a un templo de tipo itálico inscrito en un rectángulo $3: 2$ con una relación 1,5, que ocupa el espacio central de un posible témenos delimitado al oeste por un muro de sillares de arenisca. Desde el punto de vista edilicio destaca la forma en que está construido el basamento y el podium sobre el que se debió levantar el edificio

\footnotetext{
${ }^{2 \times}$ Pesce, G.: Nora, Guida agli scavi. Cagliari, 1972.

${ }^{29}$ Rostovtzeff, M. et alii. The temple of Adonis in the excavations at Dura Europos, New Haven, 1939, señala la existencia de una habitación dedicada a Atargartis en el santuario de Adonis.

${ }^{30}$ Will, E., Nouvelle dédicace thasienne, $B C H$, LXIV-LXV, 1940-41, 201-210. Las dos divinidades aparecen en este caso

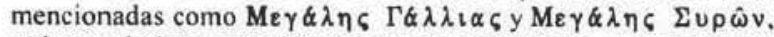
vid. para la interpretación del término $\Gamma \& \lambda \lambda \downarrow \alpha \varsigma$, esencialmente 205-208.

${ }^{31}$ Turcan, R.: Cybèles et la déesse syrienne: à propos d'un relief du Museé de Vienne (Isère), REA 63, 1961, 45-54, especialmente $52-54$, interpreta la figura femenina velada con el espejo con la Dea Syria que participa en un sacrificio dedicado a Cybeles.
}

propiamente dicho. El templo se encuadra por caracteristicas, proporciones y materiales utilizados, en toda la tradición templar de la arquitectura tardorepublicana, aunque la forma en que se erige el podium recortando la roea de base y revistiendola con un forro de pequeños bloques de tufo, remite también a ciertos edificios sacros de inspiración grecohelenistica. La anchura del edificio nos permite, en una primera aproximación, reconstruir una fachada tetrástila tal vez con capiteles jónicos de tipo itálico (con volutas en diagonal) que sigue las corrientes al uso en la arquitectura religiosa de la época tardorepublicana de finales del siglo $\|$ o los primeros años del i a.C. Sin embargo, dado lo arrasado de todo el conjunto, el único elemento arquitectónico hallado en el entorno del santuario es una basa toscana de caliza micritica gris compuesta por plinto, bocel y listel, de $0.48 \mathrm{~m}$. de diámetro ${ }^{32}$, que encuentra su paralelo más inmediato en un ejemplar del pórtico del Foro de Ampurias ${ }^{3.3}$ (fig 12). Fundamentalmente, en la arquitectura de época tardo-republicana, elementos toscánicos y dóricos suelen ser utilizados en pórticos o espacios abiertos de carácter público ${ }^{34}$. También procede del Molinete, aunque quizás del sector B, un capitel jónico-itálico con volutas en diagonal trabajado sobre caliza gris, de $60 \mathrm{~cm}$. de diámetro en el sumoscapo y una longitud de $84 \mathrm{~cm}$. en el lado del ábaco que no concuerda, ni en dimensiones, orden y material, con los elementos arquitectónicos hallados junto al edificio monumental del sector B (fig. 13). El ancho canal situado bajo el ábaco, el equino decorado con un kyma jónico de tres ovas parcialmente cubierto por las semipalmetas de tres lóbulos con el superior inclinado hacia arriba hasta tocar la superficie superior del ábaco y el collarino de perlas y astrágalos nosıremiten a un amplio conjunto de capiteles itálicos característicos de los siglos III-inicios del । a.C. En cierto modo una interpretación más local de este tipo de capitel, bien representado también por otros tres ejemplares distintos de la misma Carthago Nova, nos proporcionan los ejemplares procedentes del santuario de la Encarnación ${ }^{35}$. En cualquier caso, tanto un elemen-

\footnotetext{
32 Cfr. un paralelo muy próximo en Shoe, L. T.: Etruscan and Roman mouldings, MAAR, XXXIII, lám. XXXVIII, 4 y como capitel un ejemplar de Bulla Regia, en EAA, Atlante dei complessi figurati, Roma 1973, lám. 305, 18.

${ }^{33}$ Gimeno, J.: Estudios de arquitectura y urbanismo en las ciudades romanas del nordeste de Hispania, Madrid, 1991, 5859 , fig. 5 .

i4 Gimeno, J.: Típologia y aplicaciones de elementos dóricos y toscanos en Hispania: el modelo del N. E., AEspA, 62, 1989, $101-103$.

is Ramallo, S.: La monumentalización de los santuarios ibéricos en época tardo-republicana, Ostraka II, 1, 1993, 134.
} 


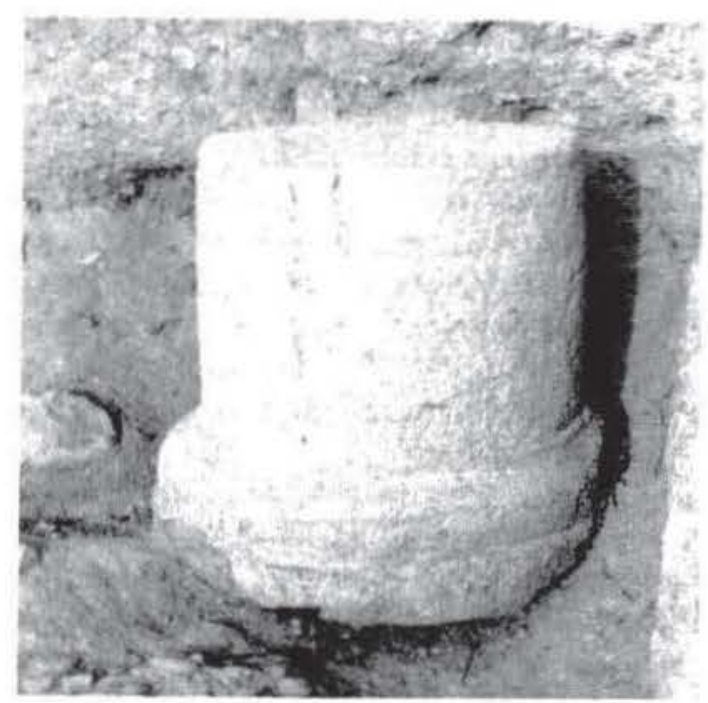

Figura 12. Basa toscana de caliza gris

to como otro. si aceptamos su pertenencia al templo, nos obligarian a restituir un edificio de fachada exástila con un módulo de aproximadamente $0.60 \mathrm{~m}$. para el diametro de la columna, un intercolumnio de $1.35 \mathrm{~m}$. y una distancia entre ejes de $2.20 \mathrm{~m}$., restitución que de momento nos parece improbable para un edificio de esta época. Más probable nos parece un edificio tetrástilo con columnas de aproximadamente $0.90 \mathrm{~m}$. y unos intercolumnios de c. $2,40 \mathrm{~m}$., siguiendo el patrón del templo de Baalshamin en Palmira ${ }^{\text {to }}$, restituido como un próstilo tetrástilo, con semicolumnas adosadas a las paredes de la cella, que ocupa aproximadamente dos tercios de la longitud total del edificio. En cierto modo, un paralelo muy similar en cuanto a aspecto. dimensiones y probablemente cronologia nos lo proporciona el templo de planta rectangular de la acrópolis de Tivoli, tradicionalmente restituido como jónico, próstilo y tetrástilo, alzado sobre un alto podium y con muros de opus quadratum unidos a hueso en las paredes de la cella. La ancha escalinata frontal y las estrechas antas del podium que parecen deducirse de la inclinación de la rampa y las improntas de arenisca identificadas en el lado oeste, nos lleva a considerar el aspecto del frontal similar al del Capitolium de Cosa, aunque en este caso se trate de un templo toscánico con cella tripartita. En cuanto a dimensiones se hallaria próximo a los parámetros del templo republicano de Vastogirardi $(10,81 \times 17,92 \times 1,83 \mathrm{~m}$.) restituido en alzado como

in Collari, J. y Vicari, Ja Le Sancruarie de Baalshamin a Palmira. Topographic et Architecture, vol. I y II. Instituto Suisse de Rome, 1969.
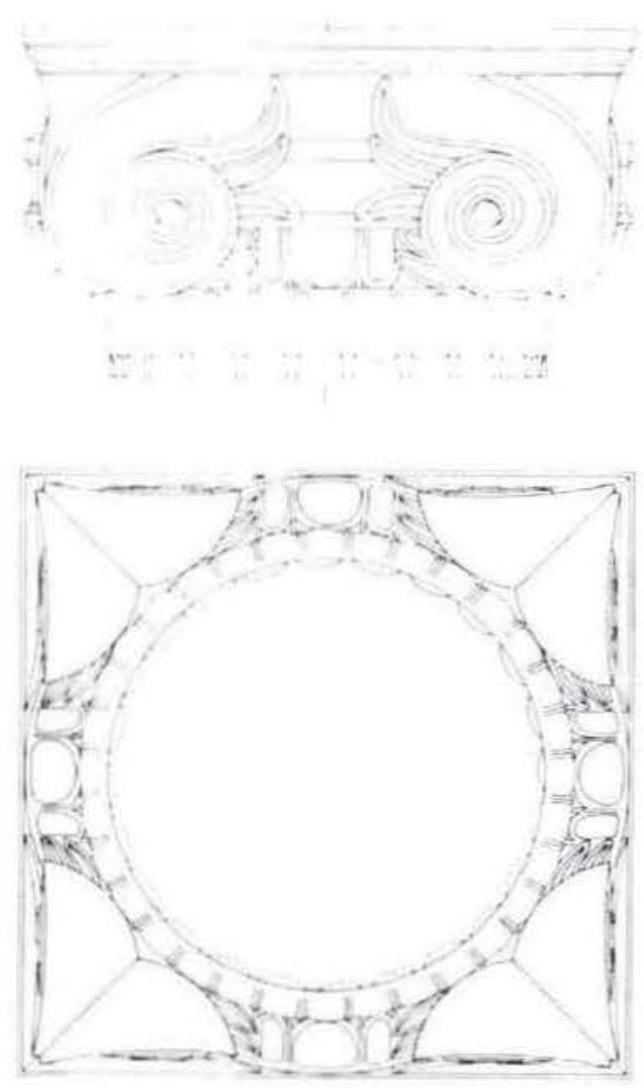

Iigur. 13-Capitel jonteo del Molinete. E. 1:15

próstilo, tetrástilo y con la cella algo más ancha que larga.

El templo parece ocupar el espacio central y el cje de simetria de un recinto sacro o témenos cuyos limites no hemos podido identificar con precisión pero que se pueden intuir por las escasas trazas conservadas y sobre todo por la propia topografia del terreno en que se asienta. Dos sillares de arenisca, material utilizado para la plataforma de cimentación del templo, situados a $8 \mathrm{~m}$. hacia el oeste, parecen marcar la linea de cierre del complejo por este lado, que en gran parte se cimentaria directamente sobre la roca. En consecuencia hay que sospechar un segundo muro paralelo a éste y a igual distancia por el lado oriental, lo que nos proporciona una anchura total para la terraza de c. $27 \mathrm{~m}$. En cuanto a la longitud total en el eje norte-sur, es más dificil de determinar dado que la muralla del siglo xvı ha cortado el edificio. Por el sur, en correspondencia con el frente 
de la fachada del edificio. el limite vendria determinado por el contorno de la propia terraza situado aproximadamente a unos $4 \mathrm{~m}$. respecto de la fachada, mientras que por el norte es dificil discernir el final, dado que la muralla del siglo xvi ha cortado transversalmente las estructuras. Sin embargo hay que sospechar que el edificio no se prolongaria mucho más de los limites conocidos dado el fuerte desnivel que existe en la parte posterior, que en parte debió ser utilizado precisamente para reforzar el carácter defensivo de la muralla. En principio, y a juzgar por los testimonios conservados, habria que intuir por tanto un espacio cerrado por tres lados con anchos muros, aunque de momento sea imposible señalar la existencia de otro pórtico, al modo de las plazas porticadas de los santuarios de Asklepios o de Serapis en Ampurias que, en cierto modo, podrían constituir los paralelos más próximos.

En el ángulo noroeste de este recinto y en la parte posterior del templo, se hallan situados el ediculo dedicado a Atargatis y las instalaciones hídricas con él vinculadas. En este caso la estructuración e interpretación de este sector del edificio es más compleja, ya que los paralelos son mucho más reducidos y la tipología más variada. Además los conjuntos arquitectónicos que conocemos son, salvo el santuario de Delos, en su mayor parte complejos monumentalizados en época imperial avanzada y que ofrecen pocas concomitancias con el del Molinete. La única referencia válida desde el punto de vista cronológico y arquitectónico nos la proporciona el santuario delio monumentalizado en las dos últimas décadas del siglo ॥ a.C. Inicialmente las distintas estancias del santuario se estructuraban en torno a un patio cuadrado al que se accedia a través de unos propyleos con fachada tetrástila; previamente, una larga escalera permitia salvar el desnivel desde la terraza inferior. Estos propyleos comunicaban además este sector del santuario con una larga terraza proyectada hacia el norte y bordeada hacia el oeste por un pórtico en forma de « $\pi »$ destinada a las ceremonias del culto. Junto al brazo septentrional del tripórtico existía una profunda cisterna en la que se podría rememorar el mito del "descenso del lago», mientras que el extremo septentrional del santuario estaba ocupado por salas de banquete y de baño tras las cuales se hallaba el otro ingreso al santuario ${ }^{37}$. Ya de época imperial, en el santuario de los dioses palmyrenses de Dura Europos, donde una inscripción fechada en el año 37 d.C. recuerda la cons-

17. Un breve resumen en Bruneau, Ph, y Deucat, J.: Guide de Delos, Paris, 1983, 225-227. trucción de un recinto sacro ( $\tau$ ó $\pi \circ \nu$ ) dedicado a la diosa, las capillas de culto y salas de banquete se organizan en torno a un patio cuadrado ${ }^{3 \times}$. En Palmira, en el santuario de Baalshamin, donde está atestiguado el culto a la diosa por una inscripción bilingüe (III, $n^{\circ} 45$ ), las salas de culto y banquete se organizan sobre todo al norte del gran patio rectangular, que sistematiza la mayor parte del complejo. al tiempo que las instalaciones hidráulicas relacionadas con el culto se hallan frente al templo y junto al altar de los sacrificios ${ }^{39}$.

Complejidad, dimensiones y, en definitiva, el carácter monumental de los santuarios mencionados hacen que las concomitancias que podamos señalar sean muy reducidas y que sea preciso buscar otras referencias más próximas en santuarios y capillas de tipo doméstico vinculadas a otras divinidades de procedencia oriental o norte-africana con atribuciones o cualidades similares a nuestra Atargartis. En todos ellos es una constante la existencia de piscinas rituales que se asocian a las capillas de culto propiamente dichas. En Nora, el llamado «alto lugar» de Tanit conserva un basamento rectangular donde se articulan espacios cuadrados y rectangulares y al lado una serie de piletas para abluciones. En esta misma ciudad, el templo neo-púnico, de planta compartimentada, conserva en el centro del complejo una cisterna excavada en la roca y otra más pequeña de tipo bañera ${ }^{* 0}$. En ambiente púnico, los templos de Solunto y Selinunte presentan varias habitaciones de dimensiones y caracteristicas distintas estructuradas en un espacio cuadrangular y con funciones diversas. En Solunto el altar se halla sobreelevado en una plataforma de piedra de $2 \times 1 \mathrm{~m}$. con inclinación hacia una pileta impermeabilizada de $1 \times 0,50 \mathrm{~m}$. rellena de materiales combustibles y huesos de animal. Una cisterna, una bañera y un recipiente para el agua situados al oeste parecen evidenciar la purificación de los animales antes de ser sacrificados ${ }^{41}$.

\section{CRONOLOGIÁ Y EVOLUCIÓN}

El primer problema que se plantea es determinar si el ediculo con sus instalaciones anejas y el basa-

${ }^{3 *}$ Cumont, F.: Fouilles de Doura-Europos. Paris, 1926. lám. XXV. Brown, E.: Excavations at Dura Europos, Preliminary Reports, VII-VIII, New Haven, 1939, 156-158.

30 Starcky, J.: Le sanctuaire de Báalshamin à Palmira d'apres des inscriptions, RA, 1974, 237 y también Collart, J. y Vicari, J.: Le Sanctuaire de Baalshamin a Palmira, Paris, 1969.

to Pesce, op.cit. (n. 28).

${ }^{41}$ Tussa, V., Aree sacrificali a Selinunte e a Solunto, Mozzia II, 1983, 143ss. 
mento del templo son contemporáneos y han sido realizados dentro de un mismo programa arquitectónico o si, por el contrario, corresponden a dos fases distintas aunque separadas por un corto espacio de tiempo. En este sentido sorprende, pese a la orientación común de ambas estructuras, cierto desnivel que existe entre las dos construcciones ya que la plataforma del basamento aparece ligeramente rehundida respecto a la habitación con inscripción y además no ocupa el lugar más elevado de este sector. En principio hay que considerar una cierta diacronia entre ambos edificios aunque los años transcurridos no debieron ser muchos.

Por otra parte, tipologia edilicia y materiales de construcción nos remiten sin duda a época republicana. Las rocas tufoides que constituyen el material utilizado para el alzado del muro exterior del basamento, proceden de los afloramientos próximos del Cabezo Beaza (andesitas y doleritas piroxénicas) y se hallan ampliamente documentadas en la edilicia de la ciudad ${ }^{42}$. Teselas de este material fueron también utilizadas en pavimentos de opus signinum del siglo । a.C. Asimismo el aparejo de opus reticulatum de la Torre Ciega está realizado con andesitas de Cabezo Beaza, asi como los anillos exteriores y contrafuertes del anfiteatro. Por el contrario, no se ha constatado el uso de este material en el teatro romano construido en los últimos años del siglo । a.C.

Por otra parte, las areniscas calcáreas de color amarillento utilizadas en la plataforma del basamento, proceden sin duda de los afloramientos próximos de Canteras, situados al noroeste de la ciudad. Se trata de un material que por su fácil extracción y abundancia fue ampliamente utilizado durante la época bárquida y romana, aplicándose a diversos usos. Destacan los ya citados fragmentos de friso dórico con triglifos y una cornisa con kyma jónico hallados en el sector B del Molinete y fechados en época republicana.

Para el edículo de Atargatis tenemos una referencia cronológica bastante precisa proporcionada por el propio pavimento de opus signinum que sirve de soporte a la inscripción. Esta técnica de pavimentación se halla ampliamente difundida en Cartagena al menos desde finales del siglo il a.C. y pervive hasta plena época augustea. Durante todo este periodo, un momento de gran desarrollo corresponde a finales del siglo $\|$-inicios del siglo I a.C. Se ha

\footnotetext{
42 Ramallo Asensio, S. y Arana Castillo, R.: Canteras romanas de Carthago Nova (Hispania Citerior), Murcia, 1987. $71-87$.
}

discutido mucho sobre el origen de estos pavimentos, destacando la cronologia precoz de algunos ejemplares africanos y de la Sicilia púnica para argumentar una posible creación y procedencia de ambientes púnicos. Sin embargo, en el caso concreto de Carthago Nov'a, los ejemplares que se conocen proceden de contextos romano-republicanos o, todo lo más, de época augustea. Los ejemplares más antiguos, entre los que quizá se podría incluso ubicar el de Mina Balsa (La Unión) o los de la calle Serreta y plaza de la Merced, no se pueden remontar más atrás de la segunda mitad del siglo " a.C. e incluso muy probablemente del ultimo cuarto. Seguramente en estos años de finales del siglo ॥ a.C. hay que encuadrar también el pavimento del Molinete inscrito en una amplia serie de pavimentos epigráficos cada vez mejor documentada en la ciudad ${ }^{43}$.

Desde el punto de vista filológico no sería extraño que el nombre de la divinidad estuviera expresado en dativo; la desinencia -e podría explicarse, como ha señalado Coarelli para la dedicación sobre terracota de Salus de Fregellae, como un dativo arcaico de la tercera declinación atestiguado en un cierto número de inscripciones republicanas. El paso de una forma a otra parece estar datado en los últimos años del siglo II a.C. ${ }^{44}$. En cuanto a la grafía de las letras es muy significativa la forma de la L en ángulo recto, en uso desde mediados del siglo II a.C. ${ }^{45}$. La forma de la letra $\mathrm{M}$, muy abierta, también remite a una cronología republicana ${ }^{46}$ probablemente de la segunda mitad del siglo II a.C. En general las formas de las letras tienen su paralelo más próximo en otro pavimento con inscripción de Cartagena, el ya mencionado de Iupiter Stator, datado antes de mediados del siglo I a.C. fecha de destrucción del edi-

43 En general para los pavimentos de Cartagena vid, Ramallo Asensio, S.: Mosaicos romanos de Carthago Nova (Hispania Citerior), Murcia, 1985, y la actualización reciente del mismo autor en AnMurcia, 7-8, 1991-1992, 199ss. Además del pavimento del Molinete, otros pavimentos con inscripción proceden de la calle Gisbert, Plaza de San Francisco, Cabezo Gallufo, Loma de Herrerias y villa del Rihuete y entroncan con una tradición bien atestiguada en Italia de edificios religiosos con advocaciones a la divinidad sobre el pavimento como el hallado en la lsola Tiberina con la leyenda $C$. Volcaci(us) C. $f$. Har(uspex) de stipe Iovi lurario [-m]onimentom, datado hacia mediados del siglo II a.C. (vid. Morricone Matini, M. L.: Pavimenti di signino repubblicani di Roma e dintorni. Roma, 1971, n. 3).

${ }^{44}$ Coarelli, F.: Fregellae. 2. Il santuario di Esculapio, Roma, $1986,43-44$.

ts Knud Paasch Almar, Inscriptiones Latinae, Odense, 1990, 19.

th Muess, J.: Das römische Alphabet, München, 1989, 10. Cfr. por ejemplo la grafía muy similar a la inscripción del sepulcro de Marcus Caecilius datado en la primera mitad del siglo II a.C. Knud, op.cit. (n. 45), 15. 

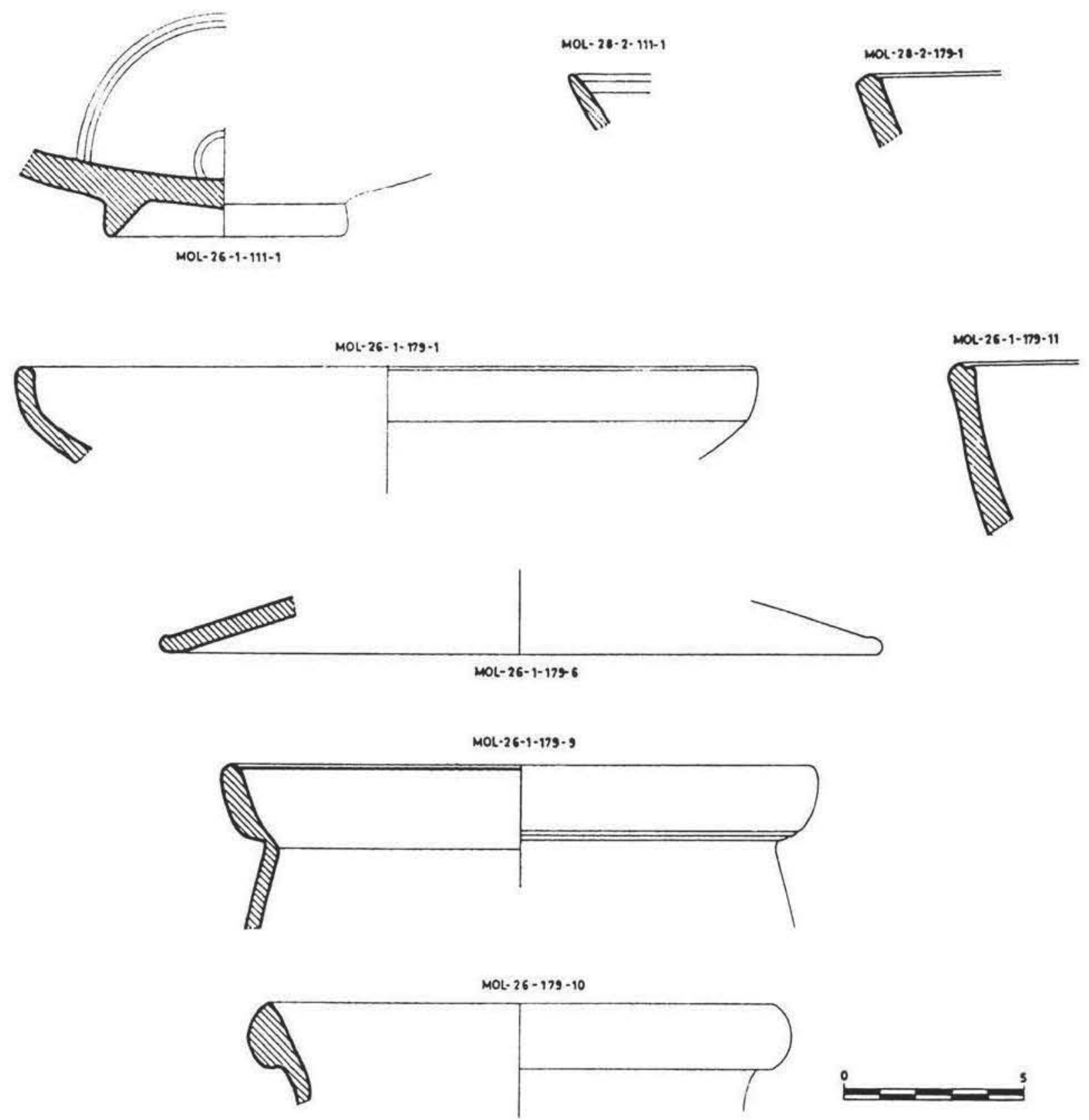

Figura 14. - Cerámicas campaniense A e italica de cocina, procedentes de los niveles subyacentes al ediculo de Atargatis. E. $1: 2$.

ficio $^{47}$. Otro paralelo nos ofrece un pavimento de opus signinum hallado bajo la iglesia de S. Giovanni Calabita de la isla Tiberina, dedicado a lupiter Iurarius fechado en torno a mediados del siglo il a.C. donde la grafia de las letras $(\mathrm{M}, \mathrm{O}, \mathrm{E})$ es bastante similar ${ }^{48}$.

47 Martin Camino, M: Cabezo Gallufo (Cartagena), $V$ Jornadas de Arqueologia Regional. Murcia, 1994, 13-14 y planta de la página 14. Vid. además el análisis filológico de la inscripción por González Fernández, R., en AntCrist, e.p.

4k Morricone Matini, M. L.: op.cit. (n. 43), 7.
En cuanto al material cerámico recogido en las excavaciones de 1977-1978, destacan ampliamente las cerámicas de barniz negro republicanas, cuyo repertorio vamos a reseñar brevemente. Estan presentes en el sector (cuadrículas X17-Y26, X17-Y25, $\mathrm{X} 18-\mathrm{Y} 25, \mathrm{X} 19-\mathrm{Y} 26, \mathrm{X} 19-\mathrm{Y} 25$ y X20-Y25) productos del área calena de la primera mitad del siglo ॥ a.C., junto a cerámicas campanienses A formas Lamboglia 27, 68, 33a, 31, 33b. Esta producción continúa presente a lo largo del siglo II a.C. con formas L. 8, 5, 6 y fondos decorados con círculos concéntricos y estampillas en forma de hoja. Del 

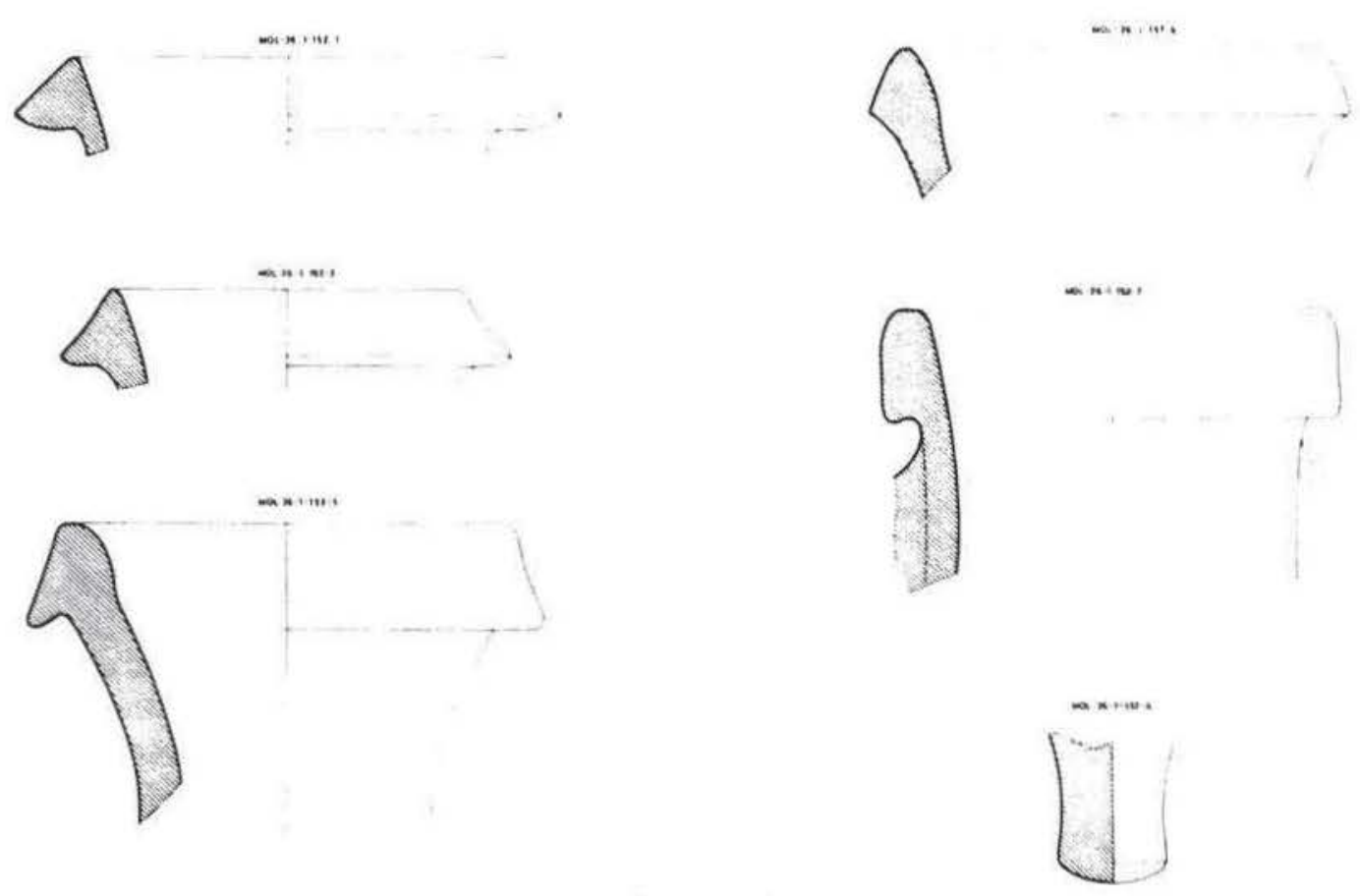

Figura 15. Anforas grecoitálicas y Dressel I procedentes de los niveles subyacentes del édiculo de Atargatis. E. 1:4

mismo ámbito caleno también proceden otros productos de la segunda mitad del siglo II a.C. con formas de campaniense B L. 1, 3 y 5. Del área etrusca encontramos ejemplares de campaniense B con formas L. 1, 3, 5, 6 y fondos decorados con sellos alternados de palmetas y flores de loto. El marco cronológico que ofrecen estos productos está fundamentalmente centrado en el siglo $\|$ a.C. e inicios del siglo t a.C. ${ }^{49}$.

Un contexto más homogéneo ofrecen los materiales cerámicos procedentes de la excavación clandestina arriba mencionada que destruyó parte de los niveles depositados bajo el pavimento de opus signinum. El material desechado, amontonado sobre el pavimento, siempre con reservas debido a su origen, ofrece una cronologia centrada en torno al 140 120 a.C. El conjunto lo componen algunos fragmentos de campaniense $\mathrm{A}$, entre los que destaca un fondo decorado con círculos concéntricos (MOL-26-111-1) muy similar a los fondos de pátera L. 5 encontrados en el pecio de Giannutri cuya cronología data del 140-130 a.C. ${ }^{50}$, cerámicas de cocina itálica pro-

4v Para el conjunto de cerámicas de barniz negro del Molinete, vid. Ruiz Valderas, E.: Las cerámicas campanienses del siglo III a.C. del cerro del Molinete, Cartagena, tesis de licenciatura inédita, Murcia, 1992.

50 En el cargamento del pecio de Giannutri, fechado en el 140-130, aparecen asociadas páteras de la forma L. 5 decoradas pias de época republicana del tipo de las ollas de borde moldurado Vegas 2 (MOL-26-1-179-9 y 10), cazuelas de borde bifido tipo Vegas 14 (MOL-262-179-11) y tapaderas de cocina (MOL-26-1-1796) ${ }^{51}$ (fig 14), junto a ánforas itálicas del grupo greco-itálico (MOL-26-1-152-1 y 2), un fragmento de ánfora de transición a la forma Dressel 1 (MOL-261-152-5), y ánforas Dressel 1 A (MOL-26-1-152-6 y 7$)^{52}$ (fig. 15). La exportación de estas ánforas Dressel I parece iniciarse hacia el 150 a.C. ya que están presentes en Carthago en niveles anteriores a la

con circulos concéntricos y ánforas Dressel 1. Lamboglia N.: La campagna 1963 sul relitto di Punta Scaleta all 'isola di Giannutri, RSL., XXX, n. 1-4, 1964, 229-257, especialmente 244ss.

"Según M. Vegas, las ollas de borde almendrado con pastas anaranjadas y superfície exterior con pátina cenicienta son frecuentes en contextos repúblicanos del siglo $\|$ y 1 a.C. Presentes en Gabii, Pollentia y como ajuar de cocina en el pecio de Albenga (fechado hacia el 90-80 a.C.). No aparecen en contextos datables'en época augústea. En cuanto a las fuentes de borde bifido con base plana y paredes ligeramente curvas. Vegas 14, es un tipo muy común en época republicana y augústea y han sido halladas en Numancia, Pollentia, Ampurias, Gabii y Pompeya. Vid. Vegas M.: La cerámica común romana en el Mediterráneo Occidental, Barcelona, 1973.

$\$ 2$ Según el sistema de M. A. Hesnard que consiste en relacionar la altura del labio con su grosor máximo, puede establecerse una evolución progresiva de las ánforas Dressel 1, como ha sido argumentado hace unos años por E. Sanmarti en su estudio sobre las ánforas del campamento numantino de Peña Re- 
destrucción de la ciudad ". Junto a este material importado destacan algunos fragmentos de cerámicas ibéricas pintadas y cerámica común de mesa, en especial una copa de imitación de la vajilla republicana de barniz negro forma L. 27 C (MOL-26-1179-1).

\section{CULTOS EN CARTHAGO NOVA EN ÉPOCA REPUBLICANA}

El texto de Polibio (X, 10, 7-11) nos ofrece el documento más amplio y explícito sobre los cultos difundidos en la ciudad durante el siglo $\|$ a.C., fecha de su visita. En su descripción de la ciudad nos dice: "La colina más alta está al este de la ciudad y se precipita en el mar; en su cima se levanta un templo a Asklepio. Hay otra colina frente a ésta, de disposición similar, en la cual se edificaron magnificos palacios reales construidos, según se dice, por Asdrubal, quien aspiraba a un poder monárquico. Las otras elevaciones del terreno, simplemente unos altozanos, rodean la parte septentrional de la ciudad. De estos tres, el orientado hacia el este se llama el de Hefesto, el que viene a continuación, el de Aletes, personaje que, al parecer, obtuvo honores divinos por haber descubierto unas minas de plata; el tercero de los altozanos lleva el nombre de Cronos) ${ }^{54}$. Salvando los problemas de orientación que ya fueron puestos de relieve por A. Beltrán ${ }^{55}$, la historiografia tradicional viene interpretando el cerro de la Concepción con la colina donde se hallaba el templo de Asklepios; en el cerro del Molinete se situaba el palacio $(a r x)$ de Asdrubal, mientras que

donda y más recientemente en el campamento de Renieblas V. Esta metodologia también es aplicable al grupo de las grecoitálicas de manera que, si lu relación es igual o menor a 0,50 , se puede asimilar a la forma Will b, más propia del siglo III a.C. e inicios del siglo II a.C.; si la relación es mayor, como el caso de las formas del Molinete, se asimilaria a Will d, datable en la primera mitad del siglo $॥$ a.C. Estas ánforas están presentes en Carthago en los momentos anteriores a su destrucción y en los mismos contextos en Ampurias. Sanmartí, E.: Las ánforas del campamento en Martino de Peña Redondo, Enuqueries, 47, 1985. 130-161s. Id.: Nouvelles données sur la chronologie du camp de Renieblas V à Numance, Documents d'archeologie Meridional 15, 1992, 417-430; Will, E. L.: Greco-italic amphoras, Hesperia, 51/3, 1982, 338-356.

33 Sobre la presencia de ánforas grecoitálicas y Dressel 1 en Carthago, Morel, J. P.: Nouvelles données sur le commerce de Carthage punique, entre le $v^{*}$ siècle et le $\|^{E}$ siècle avant J. C., $4^{*}$ Colloque international sur l'histoire et l'archeologie dell Africa du Nord. 1990, 67-100, en especial, 92ss.

54 Polibio, Historias, libros V-IV, traducción y notas de M. Balasch, Madrid, 1981, 362-363.

55 Beltrán, A.: Topografia de Carthago Nova, AEspA., XXI, 1948, 191-224. el Monte Sacro, San José y Despeñaperros correspondian respectivamente con las colinas dedicadas a Cronos, Aletes y Hefesto.

Por otra parte, la antigüedad de los cultos en la historia de la ciudad ha sido asimismo repetidas veces puesta de relieve, señalando la transposición y asimilación de las viejas deidades púnicas en sus equivalentes greco-romanas. Asklepios, sin duda la divinidad más importante en la ciudad durante gran parte del periodo republicano, es una transposición del Eshmun de (arthago donde el dios tenia un templo que era el más bello y rico de la ciudad. Cronos se ha identificado con Baal-Hammon (quizá transposición del Hadad sirio), mientras que en Hefesto se ve un sincretismo con el púnico Chusor $^{56}$. Sin embargo, y pese al acuerdo casi unánime en la investigación, no existen testimonios arqueológicos que sustenten cada una de las identificaciones.

El culto a Esculapio/Eshmun debió estar muy arraigado en la ciudad desde sus origenes, como lo estuvo en todas aquellas ciudades portuarias y especialmente en aquéllas rodeadas o próximas a lagunas o esteros de aguas semipantanosas que debian provocar frecuentes enfermedades. Al caso más conocido de Ampurias se podrian añadir otros más. De momento se han vinculado con la divinidad algunos tipos iconográficos reflejados en las emisiones monetales y también en el ara hallada (o en un primer momento conservada) en el Monte Sacro. Pero no existe ningún elemento arqueológico que se pueda atribuir sin reservas al templo hipotéticamente situado en la cima del Castillo de la Concepción ${ }^{57}$.

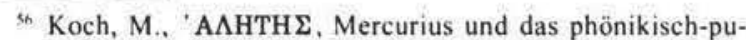
nische Pantheon in Neukhartago, MM, 23, 1982, 101-113; Bendala, M.: Die orientalischen Religionen Hispaniens, $A N R W$, II. 12, 1,363-364. Sanmartin, J.: La nueva capital: el contexto púnico de Qart-Hadast, Historia de Cartagena, vol IV*, 1992 , 94-103.

57 Precisamente en la ladera noroccidental del citado cerro fue hallado en 1989 el teatro romano que junto al anfiteatro situado en la ladera nororiental confieren a esta zona un papel destacado en cuanto a la arquitectura relacionada con los espectáculos. Sin embargo los trabajos de excavación realizados en la cima del monte, junto al actual Castillo de la Concepción han ofrecido muy escasas evidencias de construcciones romanas, tan sólo en la remoción reciente de los restos medievales y modernos se han localizado, asentados directamente sobre la roca, los restos de un muro de cierta entidad que no ha podido ser investigado en profundidad dado el ritmo acelerado de los citados trabajos de adecuación. Para los cultos a Salus y Esculapio, vid. Beltrán, A.: El ara romana del Museo de Barcelona y su relación con el culto de la Salud y Esculapio en Carthago Nova, Ampurias, IX-X, 1947-48, 213-223, y también Beltrán, A.: El culto a la Salud y sus representaciones en Elche y Cartagena, IV CASE, Elche (1948). 205-211. En Roma el culto a Esculapio se introduce en el 293 a.C. con motivo de una epidemia que asolaba la ciudad. Su templo se construyó en la isla Tiberina, probablemente sobre un culto anterior a Tiberinus, divinidad de las aguas y personificación del río. 
Desconocemos el lugar del hallazgo y el templo al que alude la inscripción CIL. II, 3421 que menciona la existencia de $\operatorname{arcos} y$ ifiltros? ([for] nices cola ante aedem) tradicionalmente vinculada a un acueducto que desde la Fuente de Cubas transportaba el agua a la ciudad ${ }^{5 x}$, pero que podria aludir también a otras instalaciones hidricas de caracter cultual relacionadas con el templo de Esculapio donde eran un elemento indispensable como se ha documentado en los santuarios orientales de Epidauro. Cos, Delos (Vitr. I,2) 5". Este culto al Dios de la medicina se extiende incluso fuera de la ciudad y se halla representado en la Cueva Negra de Fortuna, posible santuario rupestre de carácter terapeútico dedicado, al menos en parte, a las ninfas donde aparece mencionado un sacerdos Asculepi Ebusitani ${ }^{\text {til }}$. La relación, e incluso posible dependencia, de este enclave con la metrópolis cartagenera parece más que evidente.

Por el contrario, la ausencia de información arqueológica o epigráfica para los cultos o templos documentados en las fuentes escritas se completa con los testimonios que, para otras divinidades desconocidas en la literatura greco-latina referida a la ciudad, han sido recuperados en distintos puntos de su casco urbano.

El culto a Isis y a Serapis se atestigua en Cartagena a través de dos inscripciones halladas en el Molinete y en la calle Jara. Para la primera inscripción Koch duda, sin mucho fundamento, de que la procedencia original haya podido ser el cerro del Molinete, e incide en su carácter doméstico, restituyendo en la segunda linea in suo ma[ns](ionem) ${ }^{61}$. Sin embargo la existencia del ediculo de Atargatis en la misma colina podria hacernos pensar en un segundo santuario o al menos una capilla de culto doméstico, dedicado a las dos divinidades egipcias. En este sentido es interesante destacar la proximidad de los santuarios de Serapis y el de la Dea Syria en la isla de Delos ${ }^{62}$, donde también hallamos documentado el Zeus Kasios del ancla cartagenera y la inscripción funeraria de Brindisi (CIL. IX, 6099)

${ }^{9 k}$ Beltrán, A.: Las lápidas latinas religiosas y conmemorativas de Cartagena, AEspA.. 80, 1950, n. 4.

${ }^{34}$ Vid. por ejemplo, Schatzmann, P. y Herzog. R.: Kos I. Berlin, 1932; Sherwin-White, S.: Ancient Cos. Göttingen, 1978.

* Stylow, A. U. y Mayer, M.: Los tituli de la Cueva Negra. Lectura y comentario literario y paleográfico. AntCrist, IV, 1987. 198 ss.

"1 Koch, M.: Isis und Sarapis in Carthago Nova, MM, 23, 1982 , 347-352.

62 El culto a la Magna Mater se introduce en Roma en el 204 a.C. en un ambiente de crisis politica, militar y religiosa producido por la segunda guerra púnica. El templo se contruye sobre el Palatino en el interior del pomerium, ya que la diosa no era considerada una divinidad extranjera, y se inaugura en el 191 a.C. donde se documenta la existencia de una comunidad de fieles de lsis y la presencia de un sacerdocio comun entre (ibeles y Atargatis ${ }^{60}$.

Otro testiminio de la introducción oficial del culto de Isis en Carthago Nova vendria representado por las emisiones de luba II y Ptolomeo acuñadas en la ciudad a comienzos del siglo I d.C. donde se manifiestan de forma clara los atributos más especificos de la diosa egipcia. En este caso, el culto, quizás sincretizado al de Tánit/Dea Cuelestis, se instituiria de forma pública de la mano de los propios magistrados honorarios ${ }^{\mathrm{in}}$.

Mucho más interesante es el pequeño sacellum excavado en el año 1993 en el Cabezo Gallufo, junto al puerto de Santa Lucia. Consiste en dos habitaciones inscritas en un recinto rectangular de $10,45 \times 5.79 \mathrm{~m}$. con un único acceso orientado hacia el noroeste. La estancia de la derecha presenta tres basamentos rectangulares, paralelos a los muros, frente a los que discurre la inscripción realizada con teselas blancas sobre el cemento rojizo del opus signinum con la leyenda M(arcus) Aquini(us) M(arci) l(ibertus) Andro/lovi Statorid(e) s(ua) p(ecunia) qur(avit)/l(ibens) m(erito). La estancia de la izquierda muestra en el centro el ara de ofrendas y rebancos adosados a las paredes. En la parte posterior y separada por un muro más estrecho, hay un espacio reservado de menores dimensiones con una cubeta comunicada con el exterior por medio de un canal que atraviesa longitudinalmente la habitación anterior. En principio, y a juzgar por el texto de la inscripción e incluso por las características edilicias del ediculo, se trata de una advocación de carácter privado realizada por un li-

\footnotetext{
6) En este mismo contexto es muy sugerente la existencia de unos grafitos sobre platos de cerámica de barniz negro con el texto $\Sigma$ AP que podrian corresponder a una fórmula abreviada de $\Sigma A P(A I I / \Delta I)$ (fig. 16). Aparecieron entre un abundante lote de material de los siglos $\|$ al, a.C. muy cerca del conjunto que estamos analizando y podría haber formado parte de un posible depósito votivo o de ofrendas siguiendo una tradición frecuente en el mundo oriental y norteafricano. Queremos agradecer las valiosas sugerencias y observaciones del Dr. Sanmartí Grego en la identificación de estos grafitos, asi como de los doctores de Hoz y Lillo, en cuanto a los problemas de interpretación. Uno de estos grafitos ha sido interpretado en alfabeto ibérico y leido KE. KA. BI, vid. Iniesta, A. et alii: Grafitos prelatinos sobre cerámica en Murcia, $A U M$, XLIII, 3-4, 1984, 89-90, fig. VI-4. La primera y segunda letra se pueden identificar sin problemas como una sigma y una alfa, vid. por ejemplo Larfeld, W.: Handhuch der griechischen Epigraphik. Leipzig, 1902-7 (reimp. Hildesheim-Nueva York, 1971), vol. $1405-7$ y vol. II taf. II. EI problema se plantea en la interpretación de la última letra que parece más una pi que una rho, que seria lo más lógico. Las cerámicas son las siguientes: MOL-N-43-1, MOL-N-43-239 y MOL-N-53-105 (fig. 16).

${ }_{64}$ Garcia-Bellido M." P.: Las religiones orientales en la Península lbérica, AEspA, 64, 1991, 75-77.
} 


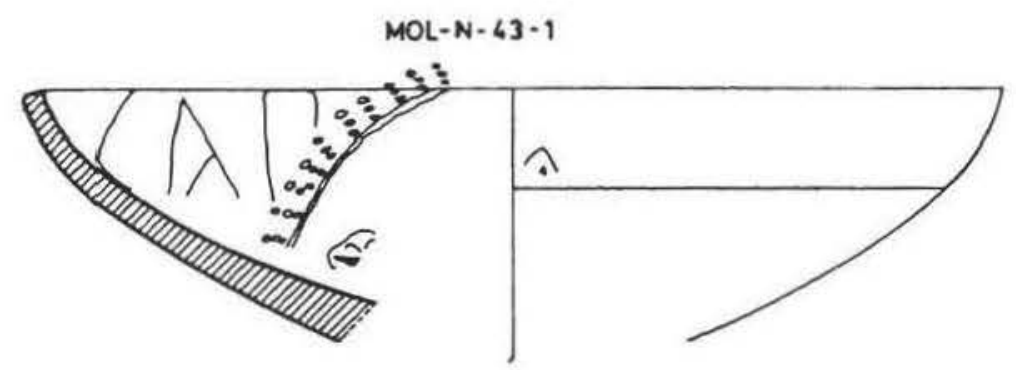

MOL-N-53-105
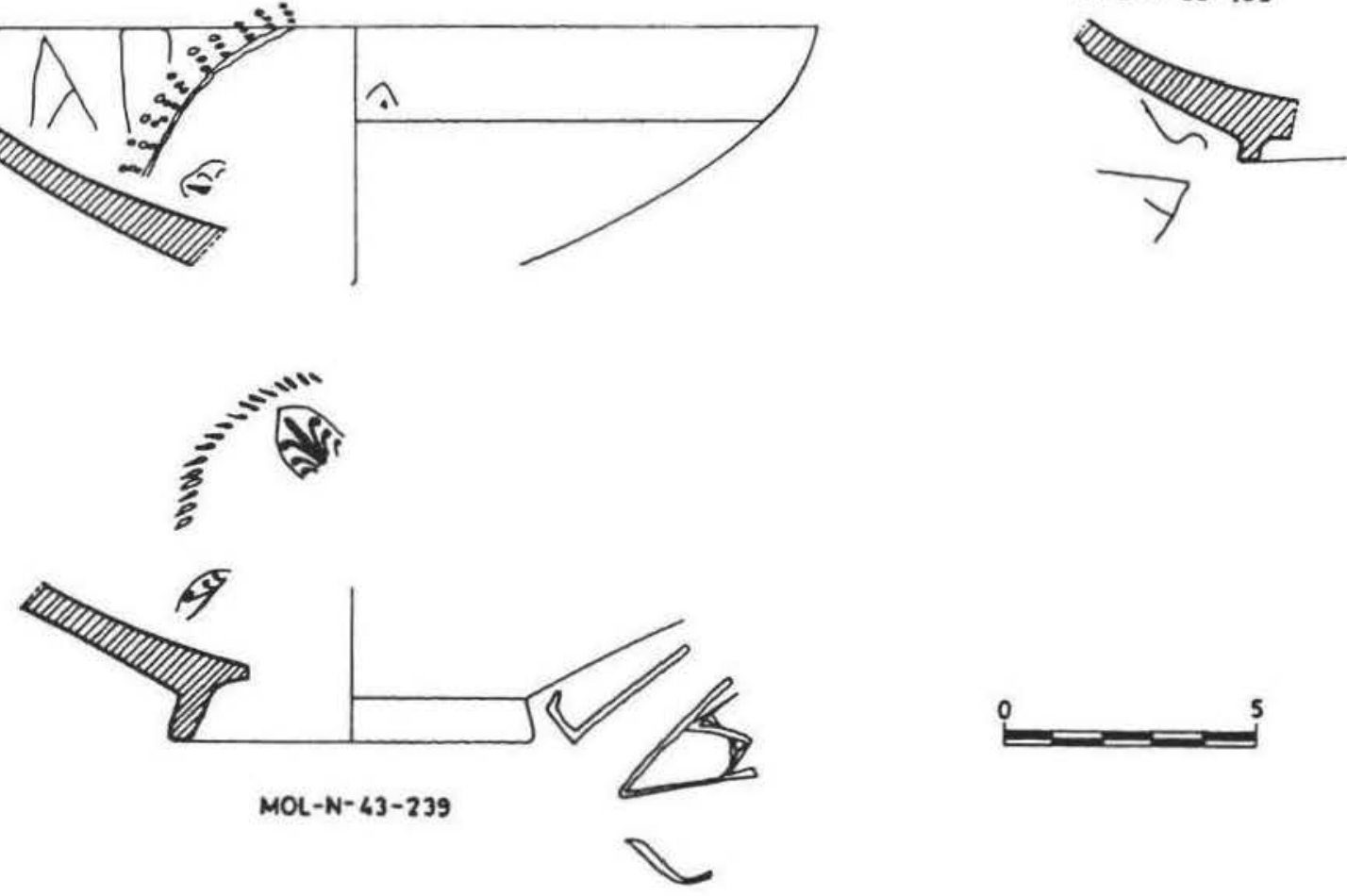

Figura 16. - Girafitos sobre platos de cerámica campaniense A que podrian corresponder a una förmula abreviada de $\Sigma \mathrm{AP}(\mathrm{AJI})$. E. $1: 2$.

berto de una de las más importantes familias vinculadas con las explotaciones mineras ${ }^{65}$. Sorprende esta advocación por parte de un liberto griego, que remite a la más vieja tradición de los origenes de Roma, ya que el templo de lupiter Stator fue fundado por Rómulo tras realizar un voto a la divinidad para que detuviera sus tropas en huida frente al avance de los sabinos; este acontecimiento se produjo en las inmediaciones de la puerta Mugonia al pie del Palatino donde, en consecuencia, fue erigido el templo ${ }^{\text {th }}$. Las estructuras de este arcaico templo han sido frecuentemente identificadas con un basamento existente junto al arco de Tito ${ }^{67}$ aunque esta interpretación ha sido rebatida recientemente por el equipo español que realiza las excavaciones en este sector

is Martin, op.cit. (n. 47) Entre las familias vinculadas con la explotación minera conocemos 12 lingotes con $C$. Aquini $M . F$, y a $M$. Aquini $C: F$. en otros diez lingotes, contemporáneos al momento de ejecución del sacellum de Cartagena. Años más tarde, $C$. Aquinus Mela, acuña como llvir quinq. junto a $P$. Baebius Pollio la emisión fechada en torno al $22 / 21$ a.C. (vid. Llorens. M." M.: La ciudad de Carthago Nova: las emisiones romanas. Murcia, 1994, 56-57 y 145). Aquinia Stratonice aparece también en una inscripción funeraria de época tardo-republicana o augustea (CIL II 3448).

on Coarelli, F.: II Foro Romano. Periodo arcaico, Roma 1986. 26-33.

67 Fasella, C.: Il c.d. tempio di Giove Statore al Foro Romano: studio preliminare, Italica 18. 1990, 135-155. del Foro ${ }^{\mathrm{tx}}$. El otro templo ofrecido a esta divinidad fue dedicado por Q. Cecilio Metello Macedónico en el 146 a.C. en la zona del Campo Marzio Meridional. Obra de Hermodoro de Salamina fue el primer edificio en Roma construido integramente en mármol. Conocemos su forma por la descripción de Vitruvio (III, 2, 5) y por algún fragmento de la Forma Urbis, y en nada se asemeja al sacellum de Cartagena, ya que en nuestro caso el edificio responde más al tipo de capilla de carácter doméstico y casi privado que a un gran edificio público. Sólo la existencia de dos estancias contiguas podria rememorar, de lejos, los dos cultos encuadrados por el porticus Metelli, el más antiguo de Iuno Regina y el instaurado por Metello a Iupiter Stator. De momento se nos escapa la razón que subyace en esta advocación y su probable relación tipológica con el prototipo palatino ${ }^{69}$ ya que el templo de Hermodoros es, según Vitruvio, un períptero canónico. Por otra parte, desconocemos cualquier posible relación en-

\footnotetext{
ox Arce, J., Sánchez Palencia, J. y Mar, R.: Monumento junto al arco de Tito en el Foro Romano (Campaña de 1989), AEspA. 62, 1989, especialmente 307-308.

${ }_{69} \mathrm{~J}$. Arce anuncia un trabajo sobre el templo palatino que esperamos sea clarificador en cuanto a la ubicación y tipologia del edificio, vid. de este autor, luppiter Stator en Roma, Ba. 1994 (e.p.).
} 
tre la familia de los Aquinios, uno de cuyos libertos dedica el edificio, y la de los Metellos. En cierto modo, la ubicación del edificio, en una posición suburbana y en la falda del monte que domina el actual puerto de Santa Lucia, una de las ensenadas mejor protegidas en toda la bahia de Cartagena y muy probablemente uno de los puertos o embarcaderos de la ciudad romana, responde a la advocación del dios «que detiene a los que huyen».

Otras divinidades atestiguadas en la ciudad cuya proyección fue menos importante $o$, al menos, no es tan conocida, son Fortuna, atestiguada en una de las arae del teatro, Mercurium (CIL. II, Add, 5929), Genio Castell(i) (Beltrán. V-1), Larib[us] (Villamarzo, 97), Lares Augustales (CIL. II, Add. 5929), Genio opidi (CIL. II, 3408), Hercule(i) Gadita(no) (CIL. II, 3409), Victoriae Augustae (CIL. II, 3410) ${ }^{7 !}$.

Esta selección de divinidades refleja ya el carácter heterogéneo y variopinto que caracteriza durante toda su historia la religión de la ciudad y que, en realidad, es un claro reflejo del carácter cosmopolita de sus ciudadanos. En ella se concitan cultos de la más rancia tradición romana con otros fuertemente arraigados entre la población semita, como el de Hércules Gaditano, heredero del Melqart fenicio.

\section{VALORACIÓN Y PERSPECTIVAS}

Si aceptamos la situación de la topografia de la ciudad transmitida por Polibio, quien sabemos que visitó la ciudad hacia mediados del siglo $\|$ a.C., esto es algunos decenios antes de la construcción del conjunto que aqui analizamos, al cerro de Molinete no corresponderia ninguno de los cultos principales mencionados por el autor. Se plantea entonces el problema de la identificación de los restos asociados a la capilla de Atargatis.

Hemos señalado más arriba la estrecha vinculación que para los romanos existe entre Magna $\mathrm{Ma}$ ter y Dea Syria. Aunque de momento no disponemos en Cartagena de testimonios epigráficos sobre el culto a la gran diosa frigia, sin embargo, en la Cueva Negra de Fortuna, hallamos en su ya citada inscripción II/4 una mención de los Phrygia numina (Cibeles y Attis) a los que en una ceremonia cul-

7a Como sintesis para la religión romana en Cartagena, Blazquez. J. M.: Städtebau und Religion in Neukarthago (Hispanien), Römische Geschichte, Altertumskunde und Epigraphik, Fest. für Artur Betz, 1985, 75-105. No disponemos de espacio ni es nuestra intención analizar de forma minuciosa todos estos cultos representados en la ciudad. tual se ofrecen o colocan estatuas o idolillos ${ }^{-1}$. En la península ibérica, su culto está ampliamente documentado en la Bética y Lusitania, mientras que en la Tarraconense las dedicaciones más frecuentes son a su compañero Attis ? Sin embargo, no hay que olvidar otras manifestaciones epigráficas e iconográficas de la divinidad femenina que demuestran la extensión del culto en los alrededores de Cartagena. En cierto modo, se puede rastrear un sincretismo claro con Cibeles-Magna Mater en la inscripción de Mazarrón dedicada a la Terra Mater, que es también un claro testimonio de culto a estas grandes divinidades femeninas protectoras de la naturaleza y la fecundidad, herederas de la primitiva Diosa Madre. En principio, pues, no parece contraproducente esta interpretración, aunque sabemos que el culto a la Magna Mater se difunde en las provincias occidentales del Imperio a partir de la época imperial.

Otra probabilidad contempla la asociación de la capilla de Atargatis al santuario de Esculapio o a alguna otra divinidad de carácter salutifero, que en la ciudad gozaron de gran predilección. Ya hemos mencionado el carácter protector que en algunas ocasiones presenta la Dea Syria a la que se hacen votos pro salute... Sin embargo somos conscientes del problema topográfico que esta interpretación plantea, ya que tradicionalmente el citado santuario, heredero del templo de Eshmun, se situaría en el Castillo de la Concepción. Conocemos el funcionamiento de estos edificios y su ritual a través de los Asclepieia orientales de Kos, Epidauro, Gortys, Paros, Pérgamo y Atenas ${ }^{3}$.

Elementos fundamentales de todos ellos eran la estancia o espacio destinado al rito de la incubatio donde los enfermos pasaban la noche, el pozo/cisterna, instalaciones de carácter hidráulico (canalizaciones) además de las aras para el sacrificio y fuentes destinadas a las abluciones y al baño ritual ${ }^{74}$. En

"Stylow y Mayer, op, cit. (n. 60), 202, llegan a intuir tras el análisis completo de este texto un posible sincretismo entre la Magna Mater y la púnica Dea Caclestix e incluso, tal vez, entre el Attis frigio, el Eshmun púnico y el Asklepios helenisticoromano.

"3endala, op. cit. (n. 56), 380-381. En general para el culto de la diosa, Graillot, H.: Le culte de cybèle. Mère des dieux à Rome et dans I'Empire Romain. Paris 1912 y Vermaseren, M. J.: Cybele and Attis. The Myth and the cult, London, 1977. Para su difusión en Hispania, además del artículo de Bendala, vid. Ortiz. C.: El culto de Cibeles en la Hispania romana, Actas del 1 Congreso Peninsular de Historia Antigua. Santiago 1988. vol. II, $441-453$

73 Ginouvés, R.: Balaneutike. Paris 1962, 349-361.

${ }^{4}$ Sanmarti, E. et alii,: Emporion: un ejemplo de monumentalización precoz en la Hispania republicana. (Los santuarios helenisticos de su sector meridional), Stadtbild und Ideologie. München, 1990), 135-143. Mar, R. y Ruiz de Arbulo, J.: Ampurias romana, Sabadell, 1993, 171-183. 
todo el proceso el agua jugaba un papel fundamental. En nuestro caso existen instalaciones de carácter hidráulico junto al templo, incluso la alineación de anforas se podria interpretar con un carácter ritual y, además, hacia el este existe lo que parece una gran cisterna asociada a pavimentos de mortero hidráulico pero, salvo en las habitaciones vinculadas a la estancia de culto, no podemos establecer una relación espacial entre los restantes elementos integrándolos en un programa arquitectónico unitario. Mucho más importante es, en cambio, el agua y las construcciones de carácter hidráulico en el sector B del Molinete asociadas a grandes sillares y elementos arquitectónicos que denotan la existencia de otro gran edificio cuya interpretación desconocemos por completo. Por el contrario, no conocemos ningún resto de estas caracteristicas en el cerro de la Concepción, si bien aqui la erección de la fortaleza medieval ha podido transformar en gran medida su fisionomia original y borrar los restos de las construcciones preexistentes. En cualquier caso, y sobre todo en el cerro de la Concepción, se plantea también el problema del agua ya que, de no existir surgencias naturales, su conducción hacia la cima parece incluso más problemática que para el Molinete.

De cualquier forma, de aceptar esta nueva ubicación del santuario de Esculapio, tal como la propuso ya Lozano ${ }^{75}$, habría que suponer un error de orientación o ubicación en Polibio. El escritor habria confundido la colina oriental por la occidental $y$, de esta manera, la acrópolis (arx) de Asdrubal habria estado situada en el cerro de la Concepción, que por su topografia tiene más aspecto de acrópolis o fortaleza, sentido éste que ha mantenido hasta nuestros días mientras que sobre la colina más aplanada, la occidental, se hallaría el templo de Esculapio, donde además no se han constatado ni identificado indicios del palacio de Asdrubal. También cabe pensar que con posterioridad a la visita de Polibio se trasladara el culto del cerro de la Concepción al cerro del Molinete, aunque esto parece más dificil de creer, teniendo en cuenta la tradición que tiene este culto en la ciudad.

Cabe una última posibilidad y es que se trate de un culto independiente a Salus, pues ambos cultos debieron gozar de la predilección entre la población, sobre todo si tenemos en cuenta la proximidad de las zonas pantanosas del Almarjal, aunque no se nos escapa que tanto Hygaea como la citada Salus solían estar asociadas, en cuanto a ubicación espacial,

75 Lozano, J.: Bastetania y Contestania del Reyno de Murcia. Murcia, 1794 (reimp. 1980), 256. eon Esculapio ${ }^{7}$. La vinculación de esta diosa con Atargatis esta atestiguada en Delos en la inscripción sobre bronce (ID. 2233).

En este contexto de divinidades de tipo terapéutico hay que considerar también al dios egipcio Serapis, atestiguado en Hispania desde la primera mitad del siglo I a.C. ${ }^{7}$. No resulta pues extraña su advocación en Cartagena si tenemos en cuenta el continuo trasiego del ejército y sobre todo la abundante población suritálica y oriental existente en la ciudad. Ya hemos señalado por otra parte la relación espacial que en Delos existe entre el santuario de la Dea Siria y los Serapieia, por lo que no es desacertado intuir la posible existencia de uno de estos santuarios o lugar del culto sobre el cerro, aunque de momento no podamos identificarlo con los restos más monumentales situados junto a la capilla de Atargatis, que, por otra parte, parece ligeramente posterior. De cualquier forma, $y$ al igual que sucede en Ampurias, el carácter de divinidad salutifera, además de protector de marineros y comerciantes, e incluso su asimilación a Esculapio con el que compartia incluso los ritos terapéuticos, favorecieron sin duda su difusión en la ciudad portuaria, donde las relaciones con los principales puertos del Mediterráneo (Alejandría, Delos, Pozzuoli, etc.) fueron frecuentes.

En este contexto de relación con los principales puertos del Mediterráneo y concretamente con las provincias orientales a través del puerto delio, encuentran su justificación las dos anclas de plomo halladas a comienzos de siglo en el litoral cartage-

2t El culto a Salus se introduce en Roma de manera oficial hacia el 303 , junto a otros cultos foráneos orientales y su templo, situado en el Quirinal junto a la porta salutaris, habria sido dedicado por el consul del 311 a.C., C. Iunius Bubulcus. La asociación de Salus y Esculapio se constata en Fregellae donde se levanta un santuario monumental aterrazado siguiendo los modelos helenísticos en los años centrales del siglo II a.C. que se instala sobre otro culto anterior dedicado a alguna divinidad de las aguas. La identificación del complejo como santuario dedicado a Esculapio viene asegurada por la inscripción del altar y por una estatua femenina en terracota con la dedicación SALUTE (Coarelli 1986, 7-10 y 44). Degrassi, D.: Il culto di Esculapio in Italia centrale durante il periodo reppublicano, En CoareIli, F. (ed): Fregellae, 2. Il santuario di Esculapio, Roma, 1986, 145-146.

"Los documentos más antiguos de su presencia en Hispania están constituidos por el santuario de Serapis en Ampurias, fechado poco antes del comedio del siglo t a.C., vid. Sanmarti et alii, op,cit. (n. 74), 119-135, y la pilastra de terracota del campamento romano de Castra Caecilia datada hacia el año 80 a.C. vid. Garcia y Bellido, A.: El culto a Serapis en la Peninsula Ibérica, $B R A H, 139,1956,296$ y Bendala, op. cit. (n. 56), 379 con la bibliografia anterior. En una inscripción de Legio dos hermanos invocan a Esculapio, Salus, Serapis e Isis, vid. Alvar, J.: El culto a Isis en Hispania, La religión romana en Hispania, Madrid, 1981, 316. 
nero con las inscripciones $Z \varepsilon \dot{v} \varsigma \mathrm{K} \alpha \dot{\alpha} \sigma$ เ (Júpiter (es el) que salva) y $A \phi \rho \circ \delta \imath \tau \eta ̀ ~ \sigma o \zeta o v ̃ o \alpha$ (Afrodita (es la) que salva) que fueron fechadas por Fita en el siglo III a.C. ${ }^{7 x}$. Zeus Kasius es el dios de la montaña Kasios en la desembocadura del Orontes. cuyo culto ha sido también atestiguado en Delos, Epidauro, Pelusión de Egipto, Atenas y Roma ${ }^{70}$. La naturaleza de este dios es algo confusa, pero debe tratarse de una de las tantas divinidades solares siriacas cuyo carácter salvador y protector de los navegantes viene atestiguada por la dedicatoria de un comerciante a Zeus Kusios mencionada por Procopio (Bell. Got. IV 22, p. 576); en esta misma faceta del dios debemos situar las anclas de Cartagena ${ }^{x 0}$. $\mathrm{Ya}$ hemos comentado el sincretismo que existe en las inscripciones del santuario de la Dea Svria de Delos entre la Atargatis, que aparece en los textos datados antes del 118/7 a.C. y la ' $\alpha \gamma \nu \grave{\eta}$ A $\phi \rho \circ \delta \imath \tau \grave{\eta} /$ $\Sigma u ́ p ı \alpha$ (ID. 2250, 2251/52) que se refleja en las inscripciones posteriores a esa fecha. Pero además, en otras inscripciones delias contemporáneas, el paredro de la diosa aparece bajo la denominación de Zeus Hadad (ID. 2256 y 2291). Otra propuesta consistiría en identificar el templo itálico del cerro del Molinete con una dedicación a la Venus-Afrodita, advocación que es frecuente en los santuarios costeros del Mediterráneo occidental y que como hemos señalado insistentemente se identifica también con Atargatis.

Dada la estrecha relación que a veces se establece entre la siria Atargatis y la fenicia Astarté es también interesante señalar el sincretismo de esta última divinidad como A frodita/Venus que está atestiguado en Erice, considerado uno de los mayores santuarios de la diosa fenicia en occidente. Conocemos la ubicación, topografia y alzado de este santuario a través de su representación en una moneda de C. Considio Noniano (c. 60-57 a.C.) donde se refleja un edificio tetrástilo de orden dórico rodeado de una cinta mural terminado en torres rectangulares. Las fuentes escritas recogen una restauración realizada según Tácito por Tiberio y según Suetonio por Claudio, quien habría restaurado, dice, el templo de Venus Ericina ${ }^{81}$, vinculado a su vez a otro

\footnotetext{
${ }^{7 x}$ Fita, F.: Inscripciones griegas, latinas y hebreas, $B R A H$ 48, 1906, 157-8 y también, Garcia y Bellido, A.: Deidades semitas en la España antigua, Sefarad, 24 (2), 1964, 268-270.

70 Drijvers, H. J. W.: Op. cit., (n. 11), 249.

*e Garcia y Bellido, A.: Op. cit.,(n. 78), 268-270.

" Cultrera, G.: II "temenos» di Afrodita Ericina e gli scavi del 1930-1931, NSc. 1935, 294-328, y tambièn Grottanelli, C.: Santuari e divinità delle colonie d'Occidente, La religione fenicie. Matrici orientali e sviluppi occidentali, Atti del Colloquio in Roma 1979 (Roma, 1981), 109-133.
}

gran santuario costero, el de la Venus Obsequens de Terracina ${ }^{x:}$.

Durante la época republicana los cultos, salvo el de Iupiter Stutor; o son sincretismos de divinidades púnicas o son cultos de procedencia oriental; sólo a partir de Augusto comenzamos a tener atestiguados cultos oficiales de la religion romana y sobre todo aquéllos especialmente vinculados al emperador. Estos cultos "extranjeros» en Cartagena están vinculados con una población artesana de libertos y comerciantes instalada muy probablemente en los barrios periféricos de la ciudad. Es evidente que son importados directamente desde oriente quizás a través del mundo delio, o bien desde las regiones del sur de Italia (especialmente la Campania) y en consecuencia en esta transmisión Roma no desempeña el papel de intermediario.

En este contexto comenzamos también a vislumbrar representaciones simbólicas, como la del pavimento del opus signimum de la plaza de la Merced, compuesta por un creciente lunar y un haz de tres rayos, que nosotros inicialmente vinculamos a una abstracción púnica del sol y la luna, pero que sin duda hay que relacionar con alguno de estos cultos "no oficiales" ${ }^{\times 3}$. El hecho de introducir elementos de carácter simbólico en los mosaicos es frecuente en algunas casas de Delos ${ }^{x+} \mathrm{y}$ se repite con frecuencia en pavimentos de opus signinum del norte de Africa y la Sicilia púnica ${ }^{\mathrm{x}}$.

El mundo delio, como ya intuíamos, juega seguramente un papel fundamental en la transmisión de una gran parte de estos cultos y si Delos es en el Mediterráneo oriental el gran puerto que centraliza y redistribuye las mercancias de oriente, además de ser el primer emporio para el comercio de esclavos, Carthago Nova se configura durante época republicana, como años más tarde nos recordará Estrabón (III,4, 6), como el gran puerto del Mediterráneo occidental, receptor y redistribuidor de mercancías procedentes de oriente e Italia y probablemente centro del lucrativo comercio de esclavos en occidente. No en vano en la segunda mitad del siglo 11 y primera mitad del siglo ı a.C. las minas de plata se hallaban

${ }^{* 2}$ Coarelli, F.: I santuari del Lazio in età repubblicana, Roma, 1987, 122.

${ }^{* 3}$ Ramallo, S.: Nuevos mosaicos en el área de Cartagena, Mosaicos romanos, in memoriam M. Fernández Galiano. Madrid, 1989, 70, fig.1.

k4 Bruneau, Ph.: Les maisons prives, Dossiers. Histoire et Archeologie, 105, 1986, 55, y Bruneau, Ph.: Les mosaïques. Exploration Archéologique de Délos, fasc. XXIX, Paris, 1972. fig. 167.

ks Fantar, M.: Pavimenta Punica et signe dit de Tanit dans les habitations de Kerkouane. StMagreb, I, 1966, 57-65, entre otras publicaciones. 
en plena producción y, en ellas, según nos describe Polibio, trabajaban cuando las visitó cuarenta mil esclavos (Estrabón. III, 2,10).

Por otra parte la existencia de un intenso tráfico maritimo con la isla de Delos se refleja muy bien en la gran cantidad de ánforas vinarias de fabricación rodia, los lagınoi hallados precisamente, en cuanto al litoral murciano se refiere, en la propia (arthago Nova. Los Nietos y Puerto de Mazarrón, importantes núcleos de explotación minera y comercio, las cerámicas de relieve del tipo conocido en la bibliografia como de «Megara» fabricadas probablemente en la costa de Asia Menor, e incluso otros productos de carácter suntuario ${ }^{\mathrm{xt}}$. Otro posible centro

*t Ramallo, S: : La ciudad romana de Carihago Nos:a: la documentacion arqueseligica. Murcia, 1989. 50-53. de transmisión de estos cultos orientales hacia oecidente puede estar constituido por algunas regiones del sur de Italia y Sicilia de donde procede también un numeroso contingente de inmigrantes que controlan parcialmente el comercio y, sobre todo, el próspero negocio de la explotación minera. Las concomitancias con algunas de las inscripciones halladas en estas regiones son también muy significativas.

En cualquier caso, el reducido carácter de nuestra intervención arqueológica, provoca que los resultados que se proponen queden abiertos a discusión y, sobre todo, pendientes de la extensión de la actuación arqueológica a la totalidad del cerro. Sólo asi podremos valorar en su justa medida el papel desempeñado por el cerro del Molinete en la historia de la ciudad durante los últimos siglos de la República. 